NASA Technical Memorandum 4595

\title{
Controlling Forebody Asymmetries in Flight- Experience With Boundary Layer Transition Strips
}

David F. Fisher Dryden Flight Research Center Edwards, California

Brent R. Cobleigh PRC Inc.

Edwards, California

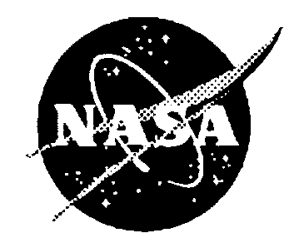

National Aeronautics and Space Administration Office of Management Scientific and Technical Information Program 1994 


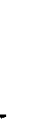




\title{
CONTROLLING FOREBODY ASYMMETRIES IN FLIGHT- EXPERIENCE WITH BOUNDARY LAYER TRANSITION STRIPS
}

\author{
David F. Fisher* \\ NASA Dryden Flight Research Center \\ P. O. Box 273 \\ Edwards, CA 93523-0273 \\ Brent R. Cobleigh"* \\ PRC Inc. \\ Edwards, CA 93523
}

\begin{abstract}
The NASA Dryden Flight Research Center has an ongoing program to investigate aircraft flight characteristics at high angles of attack. As part of this investigation, longitudinal boundary layer transition strips were installed on the F-18 HARV forebody, a preproduction F/A-18 radome with a nose-slice tendency, and the X-31 aircraft forebody and noseboom to reduce asymmetric yawing moments at high angles of attack. The transition strips were effective on the F-18 HARV at angles of attack above $60^{\circ}$. On the preproduction F/A-18 radome at an angle of attack near $50^{\circ}$ the strips were not effective. When the transition strips were installed on the X-31 noseboom, a favorable effect was observed on the yawing moment dynamics but the magnitude of the yawing moments was not decreased.

\section{Nomenclature}

$\begin{array}{ll}C_{n} & \text { yawing moment coefficient } \\ C_{n_{0}} & \text { yawing moment coefficient at zero sideslip } \\ C_{n_{0, \beta}} & \begin{array}{c}\text { yawing moment coefficient due to forebody } \\ \text { at zero sideslip }\end{array} \\ C_{p} & \text { pressure coefficient } \\ C_{Y} & \text { side-force coefficient } \\ \text { F.S. } & \text { fuselage station } \\ \text { HARV } & \text { High Alpha Research Vehicle } \\ \text { LEX } & \text { leading-edge extension }\end{array}$

\footnotetext{
"Aerospace Engineer. AIAA member.

** Aeronautical Engineer. ALAA member.

Copyright $\odot 1994$ by the American Institute of Aeronautics and Astronautics, Inc. No copyright is asserted in the United States under Title 17, U.S. Code. The U.S. Govemment has a royalty-free license to exercise all rights under the copyright claimed herein for Govemmental purposes. All other rights are reserved by the copyright owner.
}

LSB laminar separation bubble

$M \quad$ Mach number

MATV multi-axis thrust vectoring

$R \quad$ radius of forebody just forward of the canopy

$\mathrm{Re}_{\mathrm{d}} \quad$ Reynolds number based on noseboom diameter

$r \quad$ nose-tip radius of curvature

a aircraft angle of attack, deg

$\beta \quad$ aircraft angle of sideslip, deg

$\theta$ forebody circumferential angle, deg

$\phi \quad$ aircraft roll angle about the body axis, deg

\section{Introduction}

Recent attention has focused on high-angle-of-attack flight research with the F-18 High Alpha Research Vehicle (HARV), X-29A, X-31, and F-16 multi-axis thrust vectoring (MATV) programs. One thing has become clear from this research-the importance of the flow about the forebody. For example, on the X-29A, an asymmetrical forebody vortex system caused large yawing moments that switched from left at $\alpha \approx 45^{\circ}$ to right at $\alpha=50^{\circ} .^{1-2}$ On the F-18 HARV, ${ }^{3}$ flow visualization identified an interaction between the forebody and leading-edge extension (LEX) vortices that resulted in wing rock at $\alpha \approx 45^{\circ}$. The flight envelope clearance for the $\mathrm{X}-31^{4}$ has been slowed by large yawing moments believed to be caused by asymmetrical forebody vortices and has required additional wind tunnel test $^{5}$ to find a solution. Other aircraft such as the F-16 have had their useful angle-of-attack range limited because of large yawing moments caused by asymmetric forebody vortices. ${ }^{6}$ 
These yawing asymmetries may be caused by small, sometimes imperceptible, imperfections in the side-to-side symmetry of the aircraft forebodies. ${ }^{7}$ Even carefully machined forebodies and missile shapes, however, can also have large yawing moments and side forces at high angle of attack and zero sideslip. ${ }^{\text {-12 }}$ In addition, the yawing moments can and do change direction with varying angle of attack as well as body rotation.

Some high-angle-of-attack design guidelines and methodologies developed primarily from wind-tunnel data on ways to reduce forebody asymmetries have been offered by Chapman, Keener, and Malcolm ${ }^{13}$ and by Skow and Erickson. ${ }^{14}$ In some cases these guidelines have been followed, with generally favorable results. In other cases the guidelines have not been followed, with usually unfavorable results.

At NASA Dryden Flight Research Center, the use of longitudinal boundary layer transition strips to reduce wing rock and forebody yawing asymmetries was first investigated on the F-18 HARV. The lessons learned from the HARV were then applied to a standard F/A-18 aircraft, with a preproduction radome with yawing or nose-slice tendencies, and to two X-31 aircraft, which were experiencing forebody yawing asymmetries during their highangle-of-attack envelope expansion. The use of longitudinal transition strips is also being investigated in the wind tunnel to improve results at high angle of attack. With longitudinal transition strips on a wind-tunnel 6-percent scale mode! of an F-18, pressures measured on the forebody showed much better correlation with identical pressures obtaincd in flight on an F-18 aircraft than those obtained using the conventional gritting techniques. ${ }^{15}$ Hall and Banks ${ }^{16}$ also report on the use of twin grit strips, $54^{\circ}$ from the windward plane of symmetry, on a 3.5 ogive cylinder to improve the correlation of pressure and moment data over a wide range of Reynolds numbers.

This paper presents recent results obtained using twin longitudinal boundary layer transition strips. The transition strips were placed on the lower surface of these aircraft forebodies to reduce the yawing moments resulting from asymmetric forebody flows at high angles of attack. Results are presented in the form of pressure distributions, pilot comments, or aircraft yawing moments.

\section{F-18 High Alpha Research Vehicle}

Extensive surface and off-surface flow visualizations were performed on the F-18 HARV during flight testing in 1988 and 1989.3,17 At high angles of attack, surface flow visualizations using the emitted-dye technique revealed large areas of laminar flow on the forebody and the existence of laminar separation bubbles. As shown in figure 1 , at $\alpha \approx 47^{\circ}$ the laminar separation bubble extended back as far as 42 in. from the nose apex. For the same angle-of-attack range, at $\alpha=45^{\circ}$, the F-18 HARV experienced an uncontrollable wing rock motion that can cause the aircraft to roll more than $\pm 20^{\circ}$ (fig. 2). Wing rock is the uncommanded, large amplitude, lightly damped rolling motion exhibited by many aircraft and wind-tunnel models. ${ }^{18-20}$ It can take on several different forms, but for the F-18 HARV, wing rock is a random slow rolling and sideslip excursion limit cycle with a period of about $6 \mathrm{sec}$. F-18 HARV wing rock also coincides with the severe interaction of the forebody and LEX vortices as shown by smoke flow visualization. ${ }^{3}$

During a site visit, Professor Dennis Mabey* suggested that longitudinal boundary layer transition strips, applied $80^{\circ}$ from the bottom centerline starting at the radome apex and extending aft (fig. 3), might reduce or eliminate the undesired wing-rock motion. This placement of the transition strips puts them below or windward of the laminar separation bubble (fig. 1). The purpose of the strips was to transition the boundary layer from laminar to turbulent flow, causing more stable and symmetric boundary layer separation locations on the forebody, and hence, the creation of a symmetric vortex system. While the wing-rock problem was still significant with the transition strips at $\alpha=45^{\circ}$ (fig. 4), the transition strips had a positive effect, which will be described later in the Results section.

The F-18 HARV (fig. 5) is a modified full-scale development, twin-engine, single-place, fighter/attack F/A-18 aircraft. ${ }^{21}$ The aircraft was modified by adding externally mounted thrust vanes for the deflection of the exhaust to provide additional pitching and yawing control moments. The F-18 HARV used a metal flight test radome of approximately the same dimensions as the production radomes. The apex of the radome was modified by the removal of the flight test noseboom and the installation of a flush air data system..$^{22}$ The radome nose radius was approximately 1.1 in.

\section{Experiment Description}

Extensive (250) pressure measurements were made at five circumferential rings on the forebody of the F-18 HARV (fig. 6). Each orifice was connected to temperaturecontrolled electronic scanning pressure modules with a differential range of $\pm 216 \mathrm{lb} / \mathrm{ft}^{2}$. Reference pressure for the modules was supplied by a tank in the forebody, vented to the radome compartment, and monitored by a highresolution absolute pressure transducer. In-flight zero differential pressure readings were taken before each test point and were used during postflight data reduction to correct the data for calibration offsets. Accuracy for the forebody pressure measurements is estimated to be $\pm 1 \mathrm{lb} /$ $\mathrm{ft}^{2}$. Reference 23 has a more complete description of the

\footnotetext{
"Visiting Professor, Dept. of Aeronautics, Imperial College, London, and formerly with the Royal Aircraft Establishment, Bedford, England.
} 
orifice locations, some local protuberances, and the pressure instrumentation system.

Data were obtained with and without longitudinal boundary layer transition strips. The twin longitudinal boundary layer transition grit strips, earlier shown in figure 3, were applied at $\pm 80^{\circ}$ from the windward plane of symmetry and extended from 1 in. past the nose apex aft 127 in. to below the LEX apex. The transition strips consisted of \#36 Carborundum ${ }^{\text {T4 }}$ (Carborundum Abrasives Co., Niagara Falls, NY 14304) grit and were approximately $1 / 8$-in. wide. Later, a single boundary layer transition strip was also tested on the port side that was approximately $65^{\circ}$ to $70^{\circ}$ from the windward plane of symmetry. Reference 24 was used as a guide in selecting the grit size for this experiment.

Data were obtained at quasi-stabilized 1-g flight conditions at nominal altitudes of 20,000 and $34,000 \mathrm{ft}$. At the high angles of attack, constant altitude could not be maintained during the 1-g maneuvers and, therefore, data were obtained in a descent. Time segments of 0.4-sec duration were used for data analysis purposes, with approximately 10 time points averaged.

\section{Results}

Figure 7 presents forebody pressure distributions for the five forebody stations at $\alpha=70^{\circ}$ in the clean configuration and with the symmetric boundary layer transition strips. In figure 7(a), the clean configuration, asymmetries in the pressure distributions are especially evident at F.S. 142. The higher suction pressures on the starboard side of the forebody result in a yawing moment to starboard (pilot's right). With the symmetric boundary layer transition strips (fig. 7(b)), the pressure distributions for all five locations are very symmetric, and the footprints of the forebody vortex pair have become more pronounced at F.S.'s 70 and 85.

Figure 8 shows the effect of a single transition strip on the port (pilot's left) side of the forebody. The effect of differing boundary layer conditions is seen on the two opposite sides of the forebody such as could occur during the radome service life due to damage such as scratches, dings, or even a low-quality paint job. In figure 8(a), at $\alpha \approx 67^{\circ}$, the pressure distributions appear similar to the clean configuration at $\alpha \approx 70^{\circ}$ with high suction pressures on the starboard side. At $\alpha \approx 70^{\circ}$ (fig. 8(b)), however, the asymmetry has rapidly switched so that the higher suction pressures are on the port (pilot's left) side.

The pressures on the forebody were integrated for the clean configuration and with the boundary layer transition strips to obtain forebody yawing moments (fig. 9). The asymmetries did not become significant until $\alpha=60^{\circ}$ for the clean configuration. The symmetric transition strips reduced the forebody yawing moment to one-fourth of that for the clean configuration. With the asymmetric transition strip, the asymmetries became significant starting at $\alpha \approx 48^{\circ}$. The asymmetrical transition strip also caused the forebody yawing moment to switch signs with only a small change in angle of attack. This rapid switching from a right to a left yawing moment would be of concern to pilots.

\section{F/A-18 Aircraft}

The F/A-18 (SN-161520) (fig. 10) is a standard singleplace production aircraft used for pilot proficiency and safety chase at NASA Dryden. The aircraft carried no stores or missiles during these tests. This F/A-18 was chosen for the experiment because, up to $\alpha=54^{\circ}$ in its standard configuration, the aircraft exhibited very little yawing or nose slice tendencies. (An angle of attack of $54^{\circ}$ corresponds with full-aft stick in $1-g$ flight.) Any yawing tendency was easily controlled with the rudders.

The F/A-18 carried no research instrumentation system on board, and only pilot comments and notes were recorded during postflight debriefings. Airspeed and angle of attack were computed by the production airdata computer and displayed to the pilot on the heads-up display. Above $33^{\circ}$, the airdata computer used the inertial navigation system to compute angle of attack.

\section{Experiment Description}

For this experiment, the radome of the aircraft was replaced with a preproduction radome from another F/A-18 (SN-161216) that was known to have a nose yawing tendency at $\alpha \approx 50^{\circ}$. The apex of the preproduction radome, as well as the production radomes, had a metal rain erosion cap with a 1.8 -in. diameter that protruded $-0.060 \mathrm{in}$. with a radius of curvature of $\sim 1.2 \mathrm{in}$. This preproduction radome was flight tested with and without twin boundary layer transition strips. The boundary layer transition strips of \#36 Carborundum were approximately 1/8-in. wide and were located on each side of the radome approximately $65^{\circ}$ to $70^{\circ}$ up from the windward plane of symmetry and below the location of the laminar separation bubble as seen on the F-18 HARV.

The flight test conditions flown on the F/A-18 consisted primarily of two maneuvers: a $1-g$ deceleration to full-aft stick starting at $225 \mathrm{KCAS}$ and a $90^{\circ}$-banked tum with a smooth aft stick sweep starting at $240 \mathrm{KCAS}$. These two maneuvers were performed first at $40,000 \mathrm{ft}$ and then at $20,000 \mathrm{ft}$.

\section{Results}

During the checkout flight of the F/A-18 with its original production radome, the aircraft had a slight tendency to yaw at $\alpha \approx 55^{\circ}$ but was easily controlled with the rudder. With the preproduction radome installed, during the 
1-g stalls at $40,000-\mathrm{ft}$ altitude, the aircraft yawed to the right at $\alpha=50^{\circ}$ to $55^{\circ}$ and was not controllable with the rudder. The pilots commented that there was increased wind noise about the canopy, possibly caused by vortex activity, and that the aircraft was much more susceptible to wing rock. (The table shows the pilots' comments for each maneuver flown.) At an altitude of $20,000 \mathrm{ft}$ and $\alpha \approx 50^{\circ}$ to $55^{\circ}$, the aircraft would yaw to the left, again not controllable with the rudder. During the left $90^{\circ}$-banked turns, the aircraft tended to roll out of the turn, that is, toward wings level, but did not tend to yaw or nose slice.

With the boundary layer transition strips added to the preproduction radome, the aircraft yawed to the left at altitudes of 20,000 and $40,000 \mathrm{ft}$ and $\alpha \approx 50^{\circ}$ to $55^{\circ}$ for the first pilot. During the $90^{\circ}$ left-and right-banked turns, the aircraft rolled toward wings level then yawed to the left. Between flights, it was noted that there were some rough spots from paint particles on the metal rain erosion cap at the radome apex. The metal cap then was scraped clean of paint and the burrs removed. The second pilot then flew the aircraft and observed a left yaw during the 1-g maneuver at 40,000 -ft altitude, as was observed by the first pilot. The same maneuver at an altitude of $20,000 \mathrm{ft}$ was generally symmetric but with what the pilots called "lurches." The left $90^{\circ}$-bank tums at both altitudes for the second pilot tended to roll to wings level but did not yaw; the right $90^{\circ}$-bank turns were generally symmetric.

After the flights, both pilots said they felt that the boundary transition strips did not improve the high-angleof-attack flying qualities of the aircraft with preproduction radome installed. In conversation with McDonnell Douglas engineers, they related to the authors their experience that if the radome is more than $0.015 \mathrm{in} .( \pm 0.0075 \mathrm{in}$.) out of round in the first few inches, the aircraft may have a yaw or nose-slice tendency at $\alpha=50^{\circ}$ or higher. At their plant, radomes that were as much as 0.050 in. out of round were reworked, and then no longer exhibited the yawing tendency. Radomes manufactured using a new process that greatly reduced manufacturing asymmetries have not exhibited yawing tendencies.

After the flight tests, the preproduction radome was measured for symmetry and mounted on a compound angle plate and rotated about its longitudinal axis. The basic F/A-18 radome is circular in cross-section with a $5.637^{\circ}$ nose depression or droop angle. Readings were taken circumferentially every $10^{\circ}$ with a dial gauge at intervals of 1 to 2 in. for the first 10 in., then every 5 in. for the next 15 in. The results of these measurement showed that the first 15 in. of the radome was circular within \pm 0.011 in., just slightly outside the criteria used by McDonnell Douglas. The centerline of radome at the forward measurement stations did appear to be slightly offset to the right about $0.025 \mathrm{in}$. At the tip, the rain erosion washer appeared to be offset to the right about 0.1 in., which was not unusual even for production radomes.
Pilots' comments regarding F/A-18 maneuvers flown.

\begin{tabular}{|c|c|c|c|}
\hline Maneuver & Pilot & $\begin{array}{c}\text { Clean } \\
\text { (without strips) }\end{array}$ & $\begin{array}{l}\text { With transi- } \\
\text { tion strips }\end{array}$ \\
\hline \multirow{2}{*}{$\begin{array}{l}1-g \text { deceleration } \\
\text { at } 40,000 \mathrm{ft}\end{array}$} & 1 & Yaw right & Yaw left \\
\hline & 2 & Yaw left & Yaw left \\
\hline \multirow[t]{2}{*}{$\begin{array}{l}90^{\circ} \text { left bank tum } \\
\text { at } 40,000 \mathrm{ft}\end{array}$} & 1 & $\begin{array}{l}\text { Roll out to } 45^{\circ} \\
\text { bank }\end{array}$ & $\begin{array}{l}\text { Roll right to } \\
45^{\circ} \text {, yaw } \\
\text { left }\end{array}$ \\
\hline & 2 & Roll out to $60^{\circ}$ & Right roll \\
\hline \multirow{2}{*}{$\begin{array}{l}90^{\circ} \text { right bank } \\
\text { turm at } 40,000 \\
\mathrm{ft}\end{array}$} & 1 & No slice & \\
\hline & 2 & & OK \\
\hline \multirow{2}{*}{$\begin{array}{l}1-g \text { deceleration } \\
\text { at } 20,000 \mathrm{ft}\end{array}$} & 1 & Yaw left & Yaw left \\
\hline & 2 & Yaw left & $\begin{array}{l}\text { Generally } \\
\text { symmet- } \\
\text { ric with } \\
\text { lurches }\end{array}$ \\
\hline \multirow[t]{2}{*}{$\begin{array}{l}90^{\circ} \text { left bank tum } \\
\text { at } 20,000 \mathrm{ft}\end{array}$} & 1 & Yaw right & $\begin{array}{l}\text { Roll right to } \\
45^{\circ} \text {, yaw } \\
\text { left }\end{array}$ \\
\hline & 2 & $\begin{array}{l}\text { Yaw right to } \\
\text { wings level }\end{array}$ & OK \\
\hline \multirow{2}{*}{$\begin{array}{l}90^{\circ} \text { right bank } \\
\text { tum at } 20,000 \\
\mathrm{ft}\end{array}$} & 1 & & $\begin{array}{l}\text { Roll left, } \\
\text { yaw left }\end{array}$ \\
\hline & 2 & & OK \\
\hline
\end{tabular}

\section{X-31 Aircraft}

As mentioned in the Introduction section, the flight envelope clearance for the X-31 aircraft ${ }^{4}$ had been slowed by large yawing moments believed to be caused by asymmetrical forebody vortices. With the success of the boundary layer transition strips in reducing the forebody yawing moments on the F-18 HARV, the project decided to try them on the X-31 aircraft.

Two $X-31$ research aircraft were built and have been designated ships 1 and 2 . The X-31 (fig. 11) featured a single-engine, single-place cockpit and a delta wing. For control each aircraft had a small, forward-mounted canard; single vertical tail with conventional rudder; wing leading flaps; trailing edge flaps-elevons; and three carbon-carbon paddles for vectoring the jet exhaust. Each aircraft was $43.3 \mathrm{ft}$ long, had a wingspan of $23.8 \mathrm{ft}$, weighed $12,000 \mathrm{lb}$ empty, and held $4,100 \mathrm{lb}$ of fuel in a single fuselage fuel tank.

Each aircraft had a flight test noseboom that protruded from beneath the forebody and extended 125 in. forward 
to $66.5 \mathrm{in}$. from the nosetip. The diameter of the noseboom was 3.5 in. The flight noseboom configuration, though somewhat unusual, was selected as the best configuration from several tested in subscale wind-tunnel tests because it was felt to pose the least potential dynamic problems at high angles of attack. ${ }^{25}$ Large dynamic sting loads were observed with an oscilloscope during these tests of the noseboom configurations; however, large steady-state asymmetric yawing moments were not noted during these wind-tunnel tests.

During the initial flight testing, the X-31 forebody nose radius was extremely sharp, $\sim 1 / 16$ in. During the flight program, a 20 -in. strake configuration was added, and the noses were rounded to 0.75 and 0.5 in. for ships 1 and 2 , respectively. ${ }^{26}$ The larger nose radii are more representative of the wind-tunnel model, both with and without the nose strakes.

Both X-31 aircraft were equipped with extensive instrumentation systems including airdata, flow angle sensors, accelerometers, rate gyros, control surface position transducers, inertial navigation unit information, and numerous control system parameters. The most important parameters used in the analysis were obtained at 50 samples $/ \mathrm{sec}$ with a 12-bit pulse code modulation data system. No forebody pressure data were obtained.

\section{Experiment Description}

During the envelope expansion flights of the X-31, the pilots reported numerous side-force kicks, which they referred to as "lurches," and other yawing asymmetries above $50^{\circ}$ angle of attack, especially on ship 2 . At this point, the aircraft were carefully weighed and inspected and no asymmetries or differences between the two aircraft stood out. In an attempt to eliminate or at least to minimize the yawing moment asymmetries on the two $X-31$ aircraft, longitudinal boundary layer transition strips were applied to the forebodies and nosebooms (fig. 12). The transition strips on the X-31 were wider than those used on the F-18 HARV - $3 / 8$ in. on the forebody and $1 / 4$ in. on the noseboom-to make them more durable and require fewer touch ups between fights. The \#30 Carborundum grit strip started at the nose tip and ran back about 56 in., stopping below the canard leading edge.

Since the noseboom was mounted under the forward portion of the forebody, at high angle of attack the noseboom wake entered the forebody flowfield. A concern over the wake of this noseboom affecting the forebody vortex development led to the installation of another transition-strip pair along the noseboom sides about $80^{\circ}$ up from the windward plane of symmetry. The goal of using these transition strips was to cause a turbulent separation from the cylindrical boom, thereby minimizing the noseboom wake.
Later in the flight test program, 20-in. long strakes were added to the most forward portion of the X-31 forebody. This configuration was also flown with and without transition strips starting from the aft end of the strake.

An analysis of the effect of the boundary layer transition strips was accomplished by estimating the yawing moment asymmetry from the flight data. Figure 13 gives a block diagram of this method. The flight measured data are substituted into the rigid body yawing moment equation to calculate a time history of the total yawing moment on the aircraft during a maneuver. The same data are also run through the $\mathrm{X}-31$ aerodynamic and thrust simulation databases to get a time history of the predicted yawing moment. The difference between the calculated and predicted yawing moment time histories gives the missing or unmodeled yawing moment, $\Delta C_{n}$. By restricting the analysis to symmetrical maneuvers in which sideslip, roll rate, and yaw rate are small, the unmodeled yawing moment can be attributed to asymmetries on the aircraft; $C_{n_{0}}$. $\Delta C_{n}$. Plotting yawing moment asymmetry from multiple maneuvers of the same configuration against the angle of attack resulted in a fingerprint of the asymmetry characteristic of the configuration, which then could be compared with other modified configurations.

Flight data were analyzed for symmetrical $1-g$ decelerations to high-angle-of-attack conditions and in elevated- $g$, split-S maneuvers. The elevated- $g$ maneuvers were very repeatable since the control system limited the angle-ofattack rate to $25 \% \mathrm{sec}$ during each maneuver. The maneuvers each started from nominal altitudes of 13,000,20,000, and $30,000 \mathrm{ft}$. The target angles of attack for the elevated- $g$ maneuvers were $40^{\circ}, 50^{\circ}, 60^{\circ}$, and $70^{\circ}$.

\section{Results}

The 1-g, high-angle-of-attack envelope expansion above $\alpha=50^{\circ}$ was initiated on X-31 ship 2. As stated earlier, the pilots had reported deficiencies in flying qualities at high angles of attack, as a result of yawing moment asymmetries. Figure 14(a) shows the yawing moment for the clean forebody configuration as a function of angle of attack for five different $1-g$ decelerations. As can be seen, the clean forebody produces an asymmetric yawing moment that is very random, although the magnitude of the asymmetry appears to be bounded at $\left|C_{n_{0}}\right|<0.080$. The introduction of the forebody and noseboom boundary layer transition strips results in a more repeatable asymmetry with angle of attack (fig. 14(b)). A band of yawing moment asymmetries exists for this configuration as shown. Although the asymmetry is more predictable with the transition strip than without it, the magnitude of the maximum asymmetry actually increases to almost $\left|C_{n_{0}}\right|=0.100$. The initial asymmetry is to the right, reaching a peak of $C_{n_{0}}=0.050$ 
at $48^{\circ}<\alpha<54^{\circ}$. As the angle of attack increases, the asymmetry switches to the left, eventually reaching its maximum asymmetry near $\alpha=67^{\circ}$. Although the magnitude of the asymmetry is larger with the transition strip than without it, the pilot comments were generally favorable for the grit strip. This was primarily a result of the reduction in the random behavior of the aircraft with the transition strip in place. With this configuration, the $X-31$ successfully completed its $1-g$ flight envelope expansion to $\alpha=70^{\circ}$.

In further tests on X-31 ship 2, the transition strips on the noseboom were removed to evaluate the forebody transition strips only. Figure 14(b) shows the results from the 1-g tests plotted along with the data from tests with the noseboom strips on. Two different asymmetry pattems appear based on Reynolds number. Data obtained at Reynolds number conditions of $>3.5 \times 10^{5}$ have an asymmetry onset at $\alpha=46^{\circ}$, a peak asymmetry of $C_{n_{0}}=-0.070$ at $\alpha$ $=59^{\circ}$, and a small asymmetry again at $\alpha=70^{\circ}$. The data obtained at Reynolds numbers $<2.3 \times 10^{5}$ during decelerations with forebody grit have significantly worse characteristics. The initial asymmetry starts at $\alpha=38^{\circ}$ and increases to a level of $C_{n_{0}}=-0.077$ at $\alpha=52^{\circ}$. The asymmetry then rapidly changes signs, increasing to a value of $C_{n_{0}}=0.088$ by $\alpha=55^{\circ}$. Thus, the total yawing moment change $\Delta C_{n}$ over a $3^{\circ}$ angle of attack is 0.165 . This was quickly rated as unacceptable by the test pilot.

As a result the boundary layer transition strip was reinstalled on the noseboom. These Reynolds numbers coincide very closely with the critical Reynolds numbers for cylinders in cross-flow. The lower Reynolds-number value is very near the upper bound for laminar flow about a cylinder, $2 \times 10^{5}$, while the higher Reynolds number value is very near the lower bound for turbulent flow, $4 \times 10^{5}$. The noseboom transition strip caused turbulent boundary layer separation and reduced the sudden changes in yawing moment.

The $1-g$ evaluation of the yawing moment asymmetries on the X-31 ship 1 found that much lower levels of asymmetry were present than on ship 2 . Figure 15 shows the asymmetry fingerprint for the clean and transition-stripinstalled configurations. The clean forebody configuration has a repeatable asymmetry that initiates at $\alpha=48^{\circ}$ and builds to a peak of $C_{n_{0}}=-0.063$ at about $\alpha=57^{\circ}$. This is unlike ship 2, which did not have a repeatable pattern with this configuration. The asymmetry diminished significantly by $65^{\circ}$ angle of attack. The installation of the noseboom and forebody boundary layer transition strips increased the maximum asymmetry found to $C_{n_{0}}=$ -0.078 .

As the elevated $-g$ portion of the envelope expansion began, a departure on X-31 ship 2 from controlled flight occurred during a 2-g split-S maneuver to $\alpha=60^{\circ} .{ }^{27}$ Data analysis showed that the departure was triggered by a large unmodeled yawing moment. Using the asymmetry calculation technique, the missing yawing moment increment was calculated and is shown in figure 16. A peak yawing moment value of $\Delta C_{n}=0.125$ is shown, although the departure initiates before the peak value is reached. The departure made it clear that the boundary layer transition strips were not sufficient to complete the elevated-g, highangle-of-attack envelope clearance.

The X-31 project was forced to try more intrusive configuration changes to control the forebody yawing moment asymmetries. A wind-tunnel test of several strake configurations was completed in the NASA Langley Research Center's 30-by-60-ft wind tunnel. ${ }^{5}$ The large amplitude asymmetry measured in flight was not predicted in the wind-tunnel test; however, some asymmetry was found over the same angle-of-attack range. A 0.6 -in. wide by 20 -in. long (full-scale dimensions) strake reduced the asymmetry on the model. This strake design was manufactured and installed on both X-31 aircraft. The aircraft nose apex was also rounded to more nearly match the windtunnel model ( $r=0.75$ in., $r / R=0.039$ on ship 1 and $r=$ 0.5 in., $r / R=0.026$ on ship 2 ). While the noseboom somewhat complicates the flow, the initial X-31 nose radius, as shown in figure 17 (modified from ref. 14), would be expected to be prone to forebody asymmetries and might be improved with further blunting. Also shown in figure 17 are the nose radius ratios for the F-18 HARV and F/A-18 aircraft. Both of these configurations have acceptable nose radii if the merits of reference 14 are applied. Flight tests of the X-31 aircraft confirmed that the present modifications did reduce the asymmetry somewhat; however, a significant amount remained. ${ }^{25}$

A second attempt to minimize the yawing asymmetry was made by adding a transition strip starting from the aft end of the strake, trailing back to the same termination point as the previous transition strip. Once again the boundary layer transition strip was found to increase the maximum yawing moment asymmetry. Figure 18 shows a comparison of strake installed on ship 1 with and without the forebody transition strip. In addition to increasing the asymmetry level, the transition strip causes the maximum asymmetry to be present over a larger angle-of-attack range. The forebody transition strips also increase the maximum asymmetry on ship 2, as shown in figure 19 . 


\section{Concluding Remarks}

The cause and cure of forebody asymmetries on aircraft flying at high angle of attack $(\alpha)$ can be very elusive. Symmetric longitudinal boundary layer transition strips were used on several aircraft configurations in an attempt to reduce asymmetric yawing moments at high angle of attack, with limited success. Some of the results obtained are as follows:

On the F-18 High Alpha Research Vehicle at $\alpha>60^{\circ}$ the boundary layer transition strips reduced the forebody yawing asymmetry; at $\alpha=70^{\circ}$ the yawing moment with the transition strips was a quarter of that for the clean configuration. An asymmetric transition strip on the F-18 HARV caused a rapid switching of the forebody yawing moments at high angle of attack.

Boundary layer transition strips did not appear to reduce significantly the yawing moment at $\alpha=50^{\circ}$ resulting from an asymmetric preproduction F/A-18 radome.

On the X-31 aircraft, symmetric boundary layer transition strips on the noseboom reduced the randomness of the forebody yawing moment asymmetries at high angle of attack. The boundary layer transition strips on the X-31 forebody did not reduce the maximum yawing moment asymmetry of the $\mathrm{X}-31$ configuration.

\section{References}

'Webster, Fredrick R. and Dana Purifoy, Maj., USAF, "X-29 High Angle-of-Attack Flying Qualities," AFFTCTR-91-15, July 1991. (Distribution authorized to U.S. Government Agencies and their contractors. Other requests for this document shall be referred to WL/FIMT, WrightPatterson AFB, OH 45433-6523.)

${ }^{2}$ Del Frate, John H. and John A. Saltzman, In-Flight Flow Visualization Results From the X-29A Aircraft at High Angles of Attack, NASA TM-4430, Nov. 1992.

${ }^{3}$ Fisher, David F., John H. Del Frate, and David M. Richwine, In-Flight Flow Visualization Characteristics of the NASA F-18 High Alpha Research Vehicle at High Angles of Altack, NASA TM-4193, May 1990.

${ }^{4}$ Canter, David E. and Allen W. Groves, Comdr., USN, "X-31 Tactical Utility-Initial Results," presented at the AGARD Flight Mechanics Panel Symposium on Technologies for Highly Manoeuvrable Aircraft, Annapolis, MD, Oct. 1993.

${ }^{5}$ Croom, Mark A., David J. Fratello, Raymond D. Whipple, Matthew J. O'Rourke, and Todd W. Trilling, "Dynamic Model Testing of the X-31 Configuration for High-Angle-of-Attack Flight Dynamics Research," AIAA-93-3674 CP, Aug. 1993.
${ }^{6}$ Wilson, Donald B. and Robert C. Ettinger, Lt. Col., USAF, "F-16A/B High Angle of Attack Evaluation," AFFTC-TR-79-18, Oct. 1979. (Distribution authorized to U.S. Government Agencies and their contractors. Other requests for this document shall be referred to ASD/YP, Wright-Patterson AFB, OH 45433.)

'Degani, David and Lewis B. Schiff, "Numerical Simulation of the Effect of Spatial Disturbances on Vortex Asymmetry," AIAA Journal, vol. 29, no. 3, Jan. 1989, pp. 344-352.

${ }^{8}$ Lamont, P.J., "Pressures Around an Inclined Ogive Cylinder with Laminar, Transitional, or Turbulent Separation," AIAA Journal, vol. 20, no. 11, pp. 1492-1499.

${ }^{9}$ Coe, Paul L., Jr., Joseph R. Chambers, and William Letko, Asymmetric Lateral-Directional Characteristics of Pointed Bodies of Revolution at High Angles of Attack, NASA TN D-7095, Nov. 1972.

${ }^{10}$ Hunt, B.L., "Asymmetric Vortex Forces and Wakes on Slender Bodies (Invited Paper)," AIAA-82-1336, Aug. 1982.

${ }^{11}$ Keener, Earl R., Flow-Separation Patterns on Symmetric Forebodies, NASA TM-86016, Jan. 1986.

${ }^{12}$ Moir, I.R.M., "An Experimental Investigation of the Effect of Fineness Ratio on Lateral Force on a Pointed Slender Body of Revolution," in Vortex Flow Dynamics, AGARD-CP-494, July 1991, pp. 19-1-19-3.

${ }^{13}$ Chapman, Gary T., Earl R. Keener and Gerald N. Malcolm, "Asymmetric Aerodynamic Forces on Aircraft Forebodies at High Angles of Attack-Some Design Guides," in Stall/Spin Problems of Military Aircraft, AGARD-CP-199, Nov. 1975, pp. 12-1-12-9.

${ }^{14}$ Skow, A.M. and G.E. Erickson, "Modern Fighter Aircraft Design for High-Angle-of-Attack Maneuvering," AGARD LS-121, Dec. 1982.

${ }^{15}$ Banks, Daniel W., Robert M. Hall, Gary E. Erickson, and David F. Fisher, "Forebody Flow Field on the High Angle-of-Attack Lateral-Directional Aerodynamics of the F/A-18," AIAA-94-0170, Jan. 1994.

${ }^{16} \mathrm{Hall}$, R.M. and D.W. Banks, "Progress in Developing Gritting Techniques for High Angle of Attack Flows," AIAA 94-0169, Jan. 1994.

${ }^{17}$ Fisher, David F., John H. Del Frate, and Fanny A. Zuniga, Summary of In-Flight Flow Visualization Obtained From the NASA High Alpha Research Vehicle, NASA TM-101734, Jan. 1991. Also appears in High Angle of Altack Technology, Vol. I, NASA CP-3149, 1992, pp. 205-242. 
${ }^{18}$ Nguyen, L.T., L. Yip, and J.R. Chambers, "SelfInduced Wing Rock of Slender Delta Wings," AIAA-811883, Aug. 1981.

${ }^{19}$ Ross, A. Jean and Luat T. Nguyen, "Some Observations Regarding Wing Rock Oscillations at High Angles of Attack," AIAA-88-4371-CP, Aug. 1988.

\section{0"Manoeuvre Limitations of Combat Aircraft," AGARD-AR-155A, Aug. 1979.}

${ }^{21}$ Kempel, Robert, F-18 High Alpha Research Vehicle Description, NASA CR-186029, to be published.

2Whitmore, Stephen A., Timothy R. Moes, Terry J. Larson, Preliminary Results From A Subsonic High Angleof-Attack Flush Airdata Sensing (HI-FADS) System: Design, Calibration, and Flight Test Evaluation, NASA TM-101713, Jan. 1990.

${ }^{23}$ Fisher, David F., Daniel W. Banks, and David M. Richwine, F-18 High Alpha Research Vehicle Surface Pressures: Initial In-Flight Results and Correlation With
Flow Visualization and Wind Tunnel Data, NASA TM-101724, Aug. 1990.

${ }^{24}$ Braslow, Albert L. and Eugene C. Knox, "Simplified Method for Determination of Critical Height of Distributed Roughness Particles for Boundary Layer Transition at Mach Numbers From 0 to 5," NACA TN-4363, Sept. 1958.

${ }^{25}$ Banks, Daniel W., Gregory M. Gatlin, and John W. Paulson, Jr., Low Speed Longitudinal and LateralDirectional Aerodynamic Characteristics of the X-31 Configuration, NASA TM-4351, Oct. 1992.

${ }^{26}$ Cobleigh, Brent R., "High Angle-of-Attack Yawing Moment Asymmetry of the X-31 Aircraft From Flight Test," AIAA-94-1803, June 1994.

${ }^{27}$ Groves, Al, Comdr., USN, Fred Knox, Rogers Smith, and Jim Wisneski, Lt. Col., USAF, "X-31 Flight Test Update," in 1993 Report to the Aerospace Profession, SETP Thirty-Seventh Symposium Proceedings, (ISSN \#0742-3705), Sept. 1993.

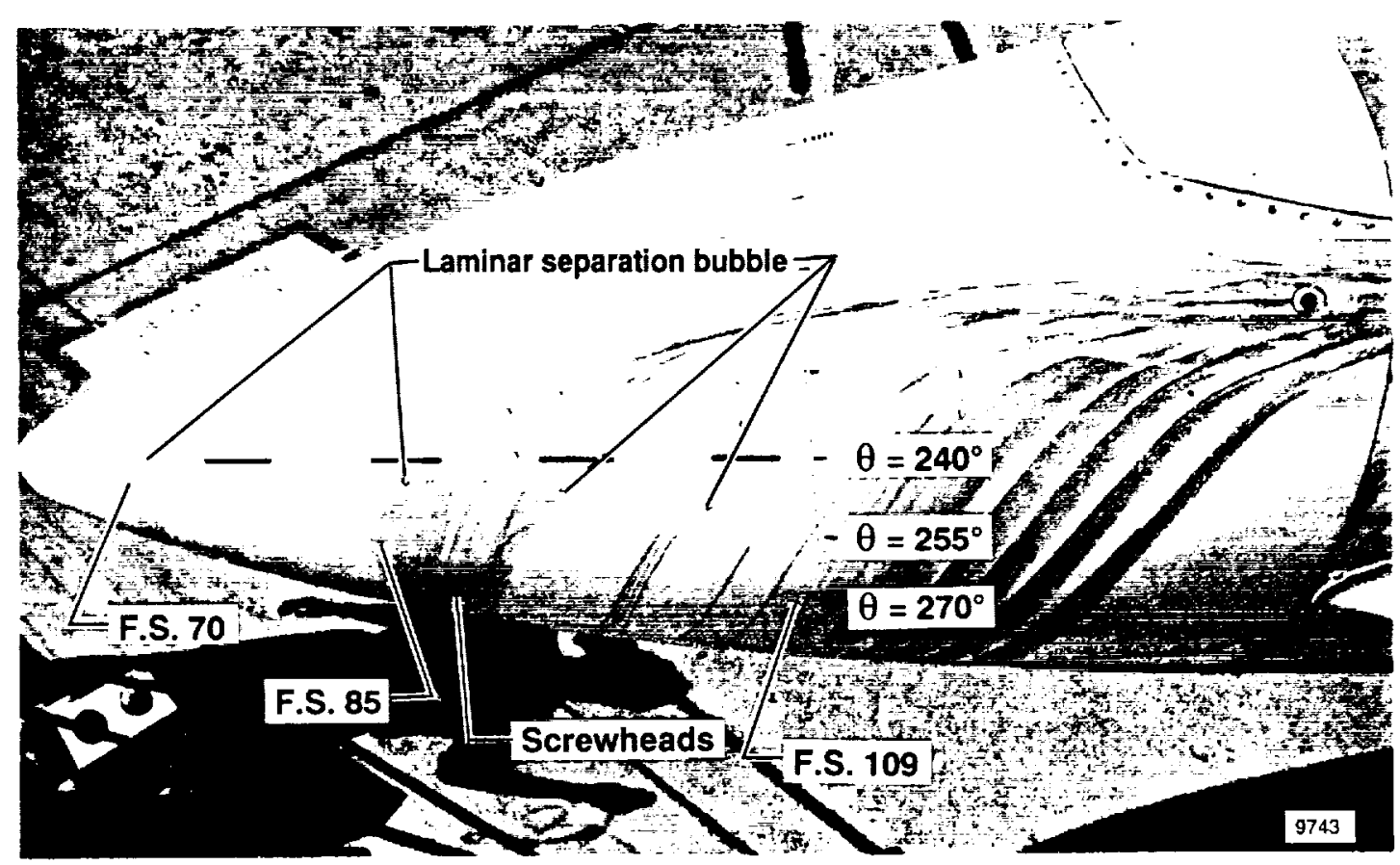

Figure 1. Nose cone of F-18 HARV, $\alpha=47^{\circ}$. 


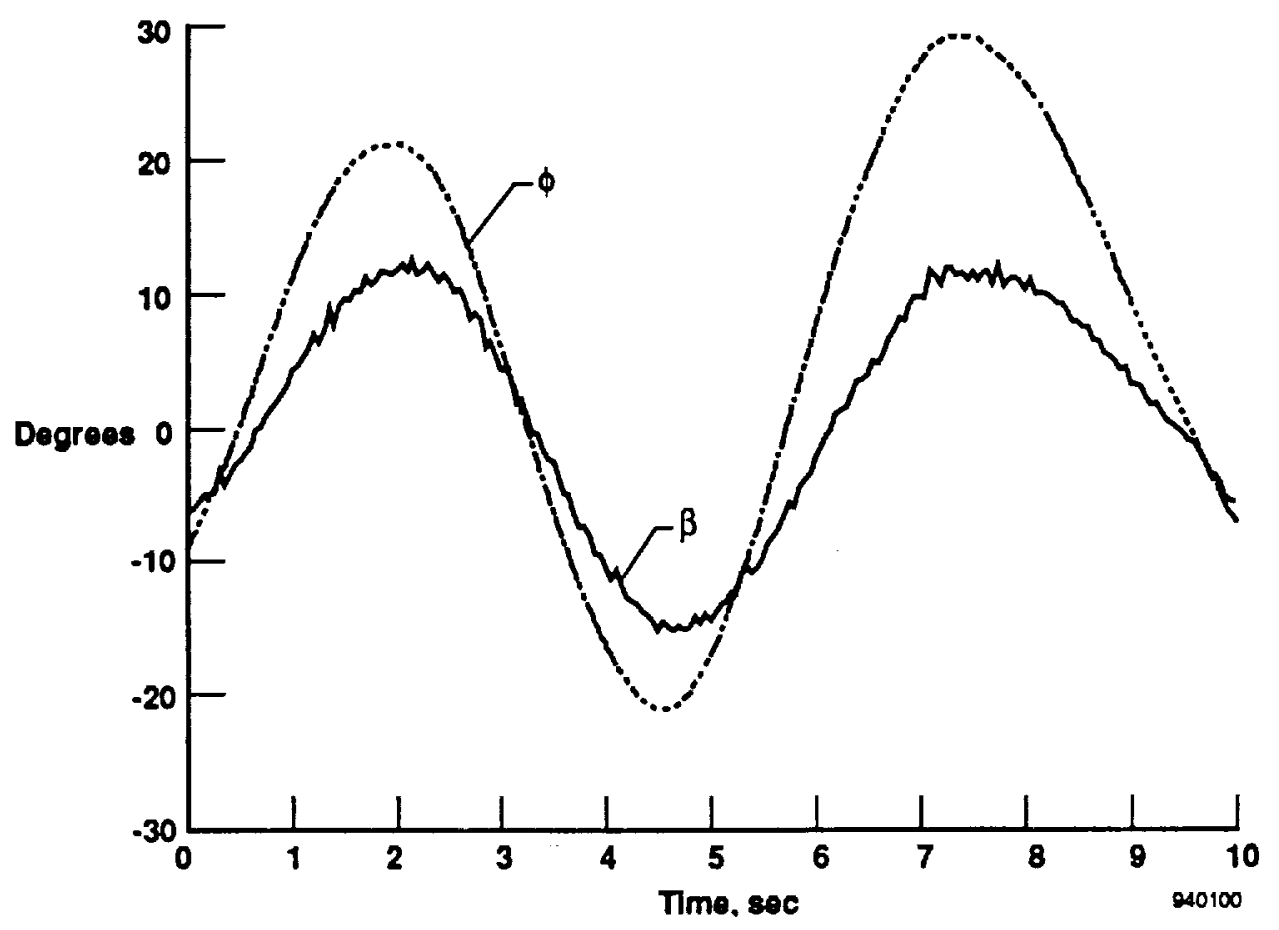

Figure 2. Time history of wing rock on F-18 HARV at $\alpha=45^{\circ}$.

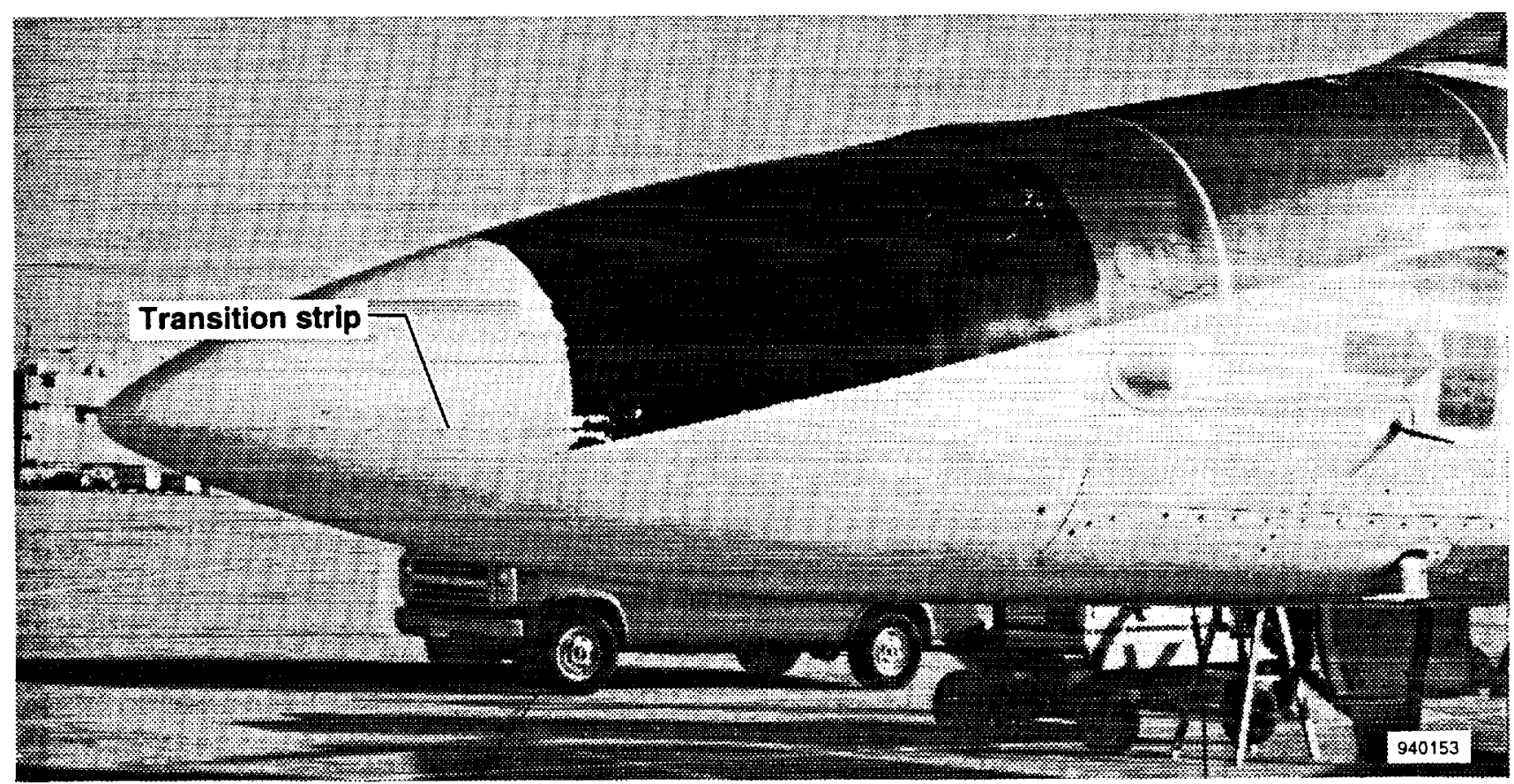

Figure 3. Boundary layer transition strip on F-18 HARV forebody. 


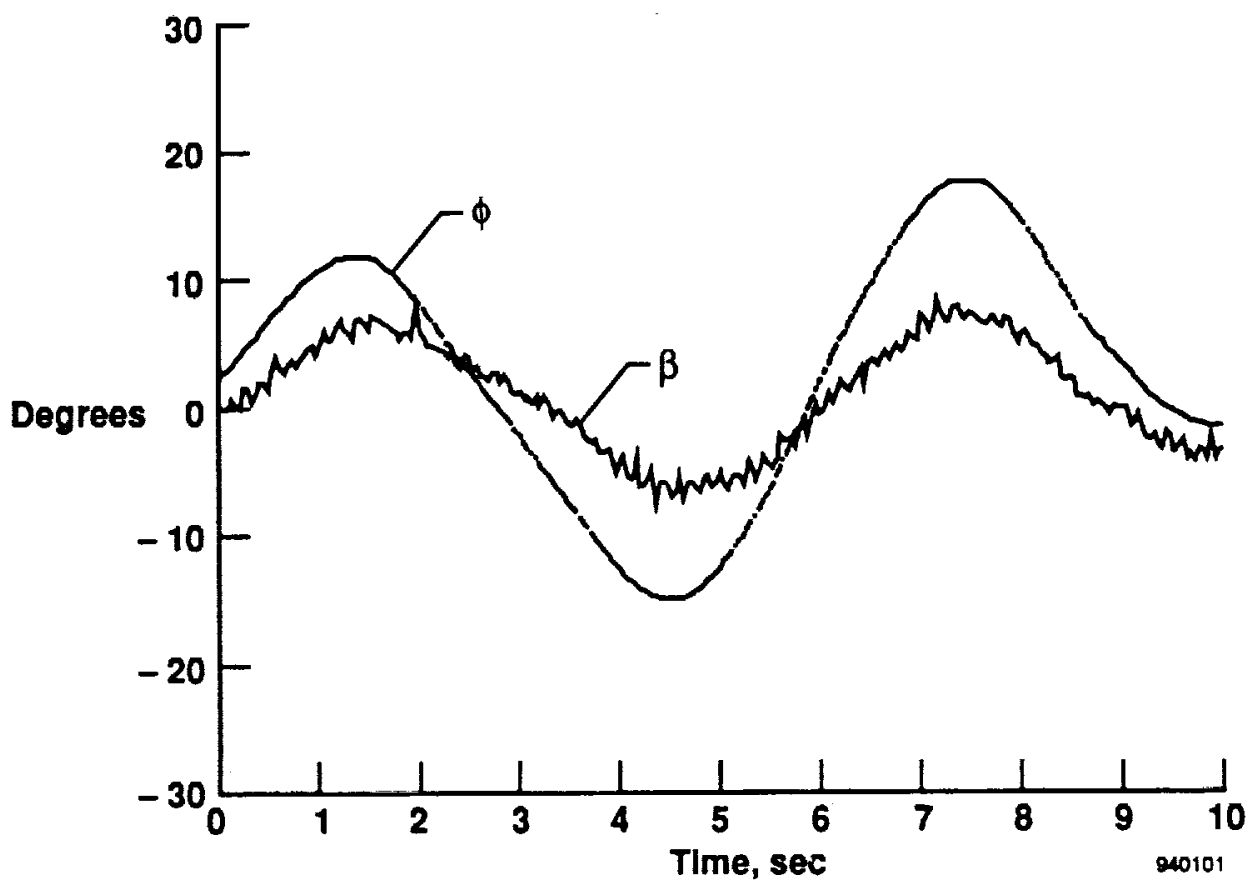

Figure 4. Time history of wing rock with transition strips installed.

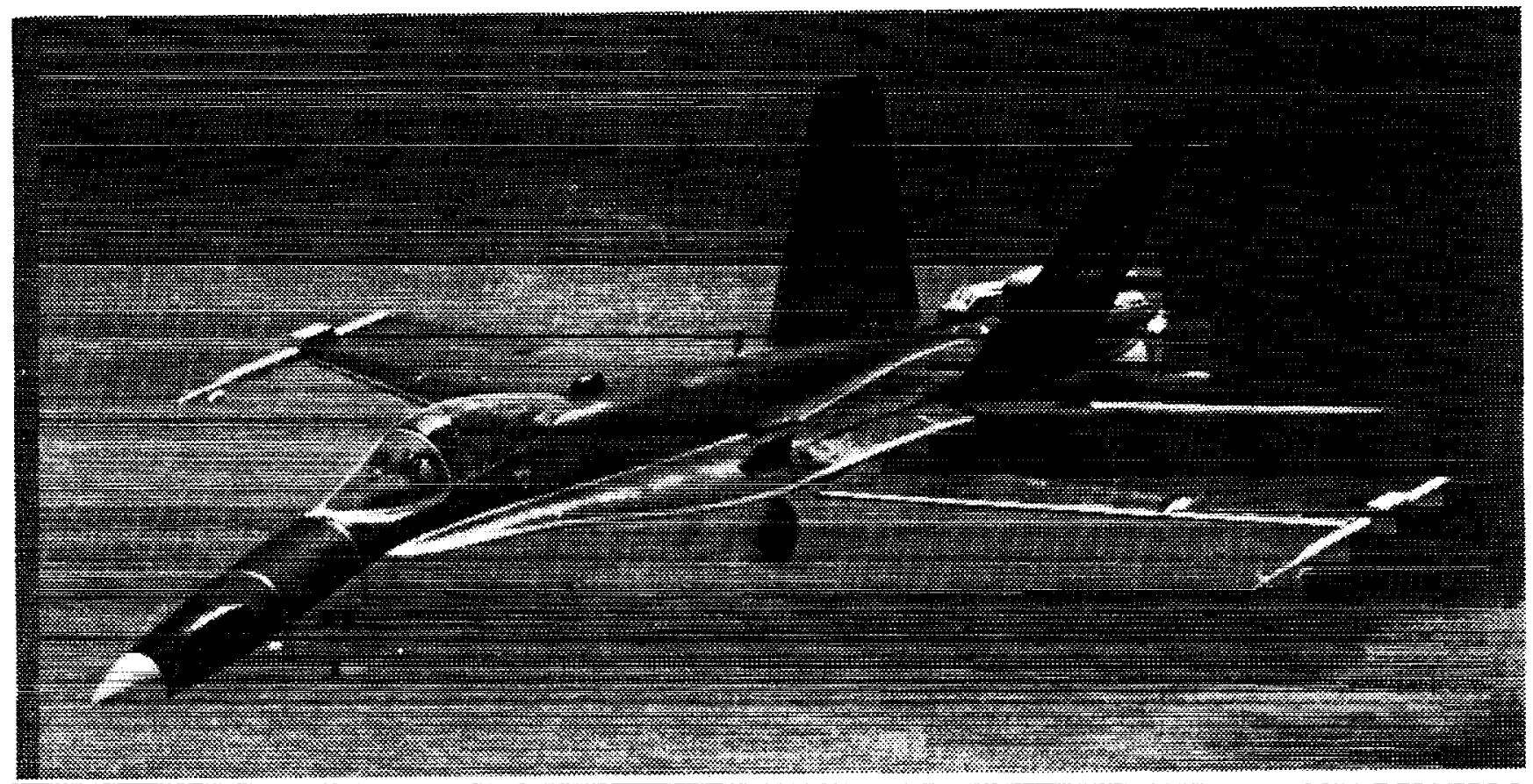

EC91-495-2

Figure 5. F-18 HARV in flight. 


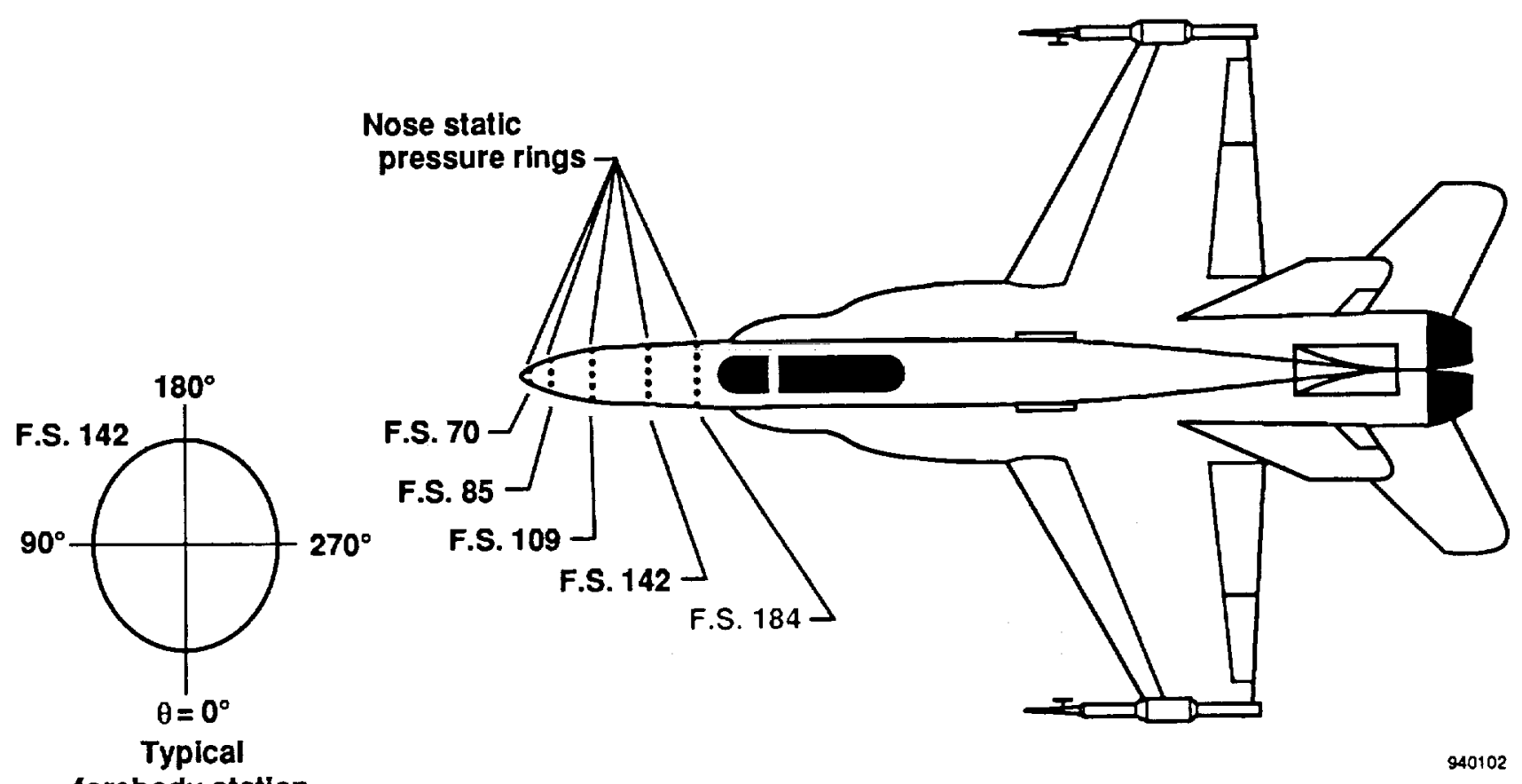
forebody station

Figure 6. Locations and orientation of forebody pressure orifices. 


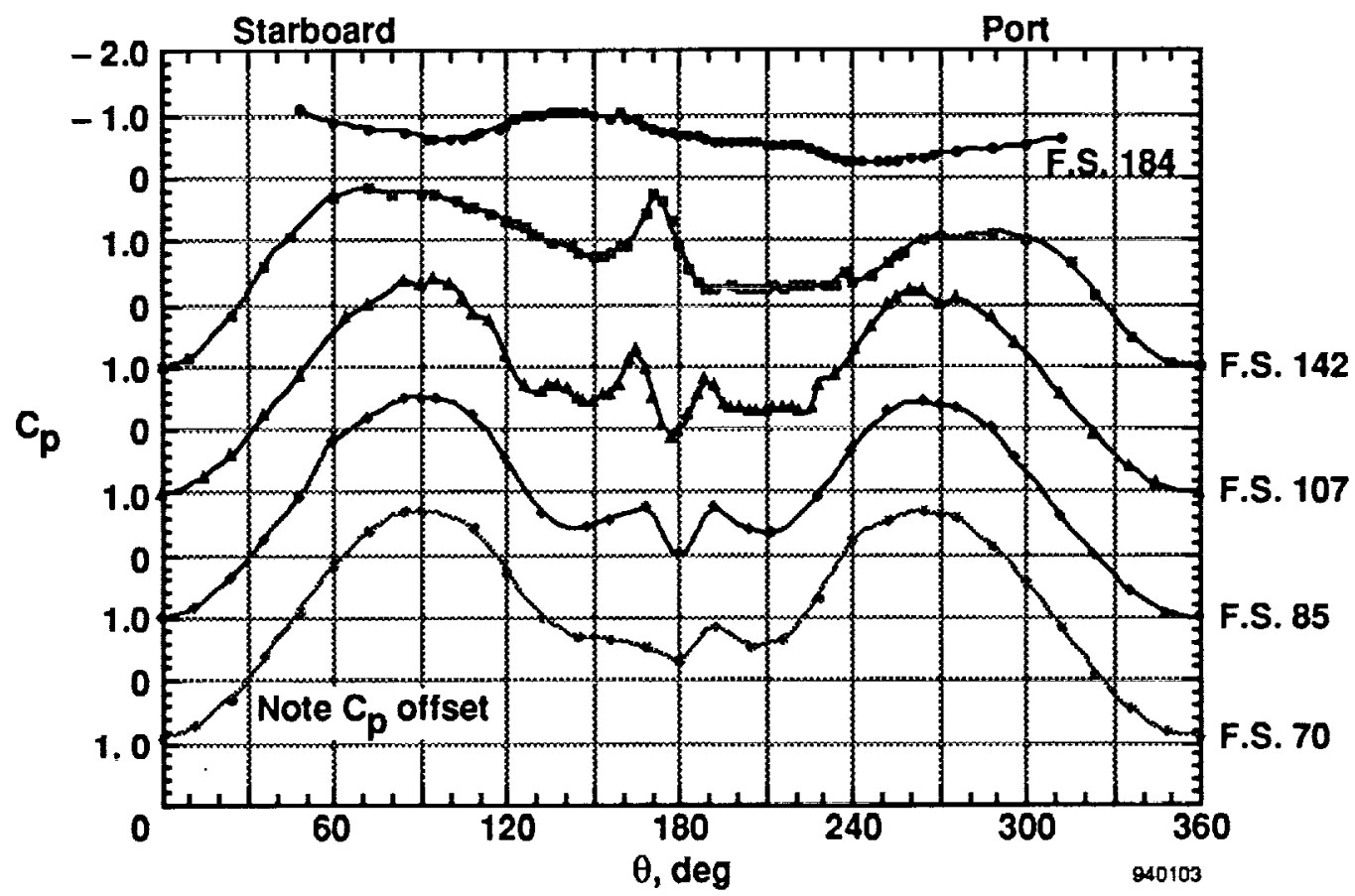

(a) Clean configuration: $\beta=-0.5^{\circ}$.

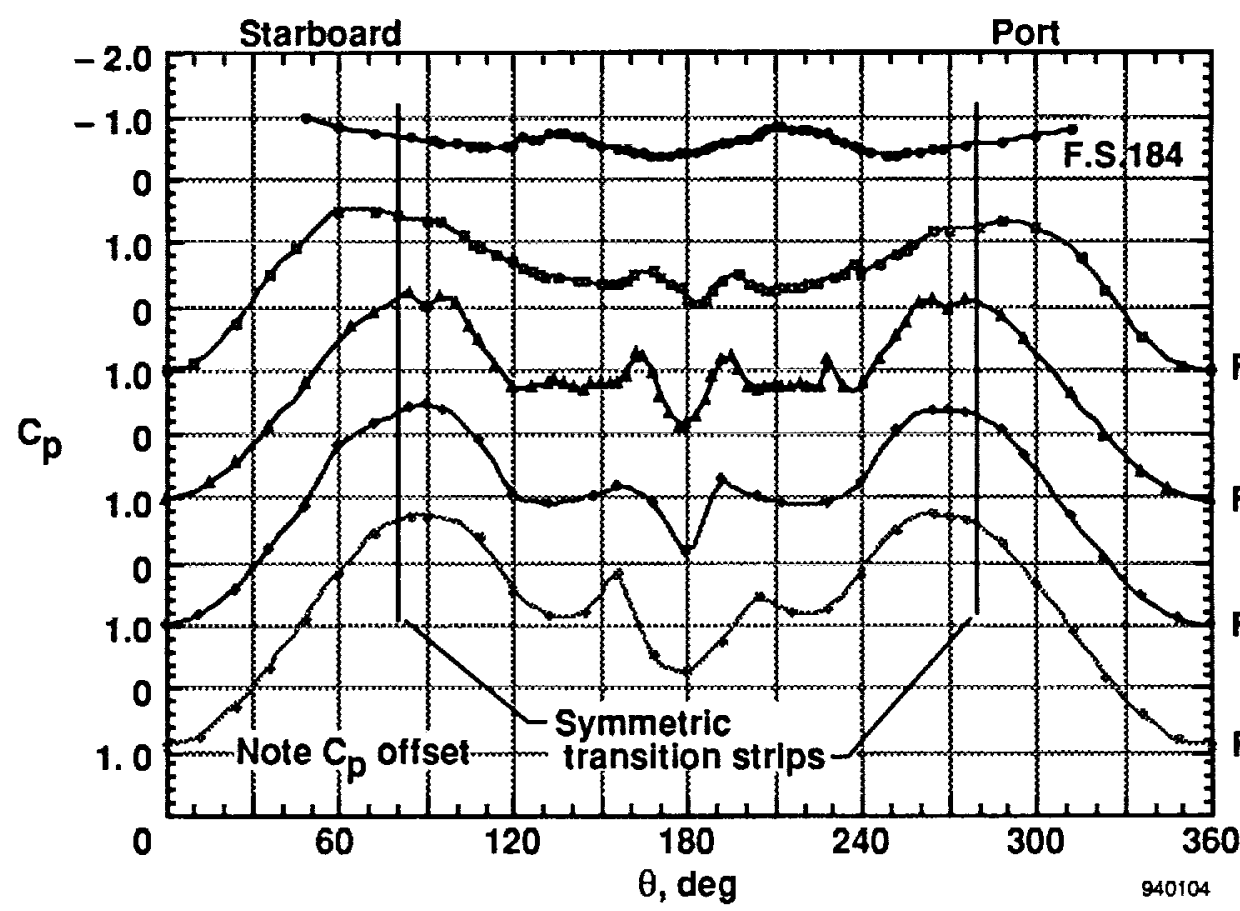

F.S. 142

F.S. 107

(b) Symmetric transition strip configuration; $\beta=0^{\circ}$.

Figure 7. F-18 HARV forebody pressure distributions, $\alpha=70^{\circ}$. 


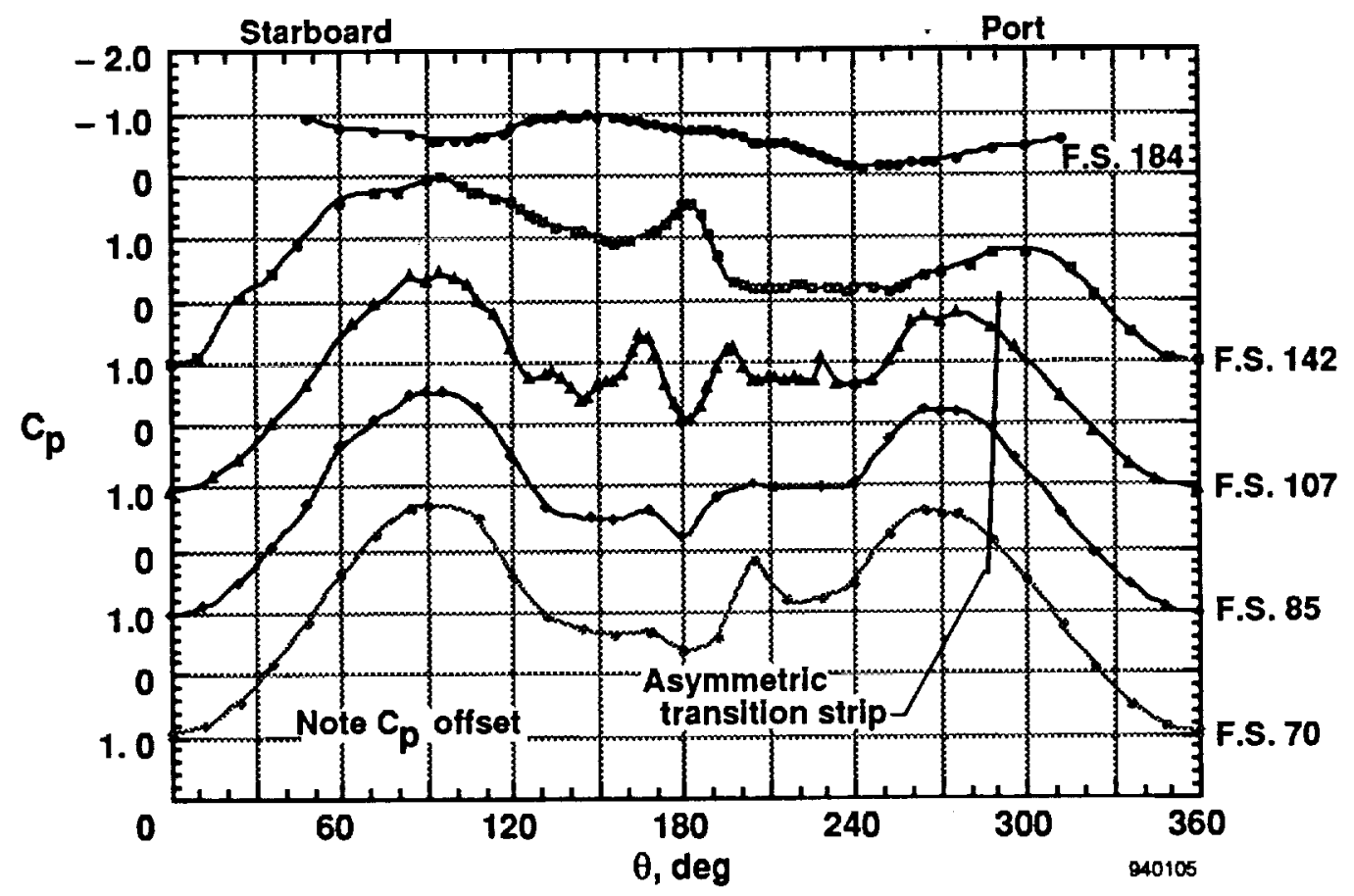

(a) Asymmetric transition strip; $\alpha=67.1^{\circ}, \beta=-0.1^{\circ}$.

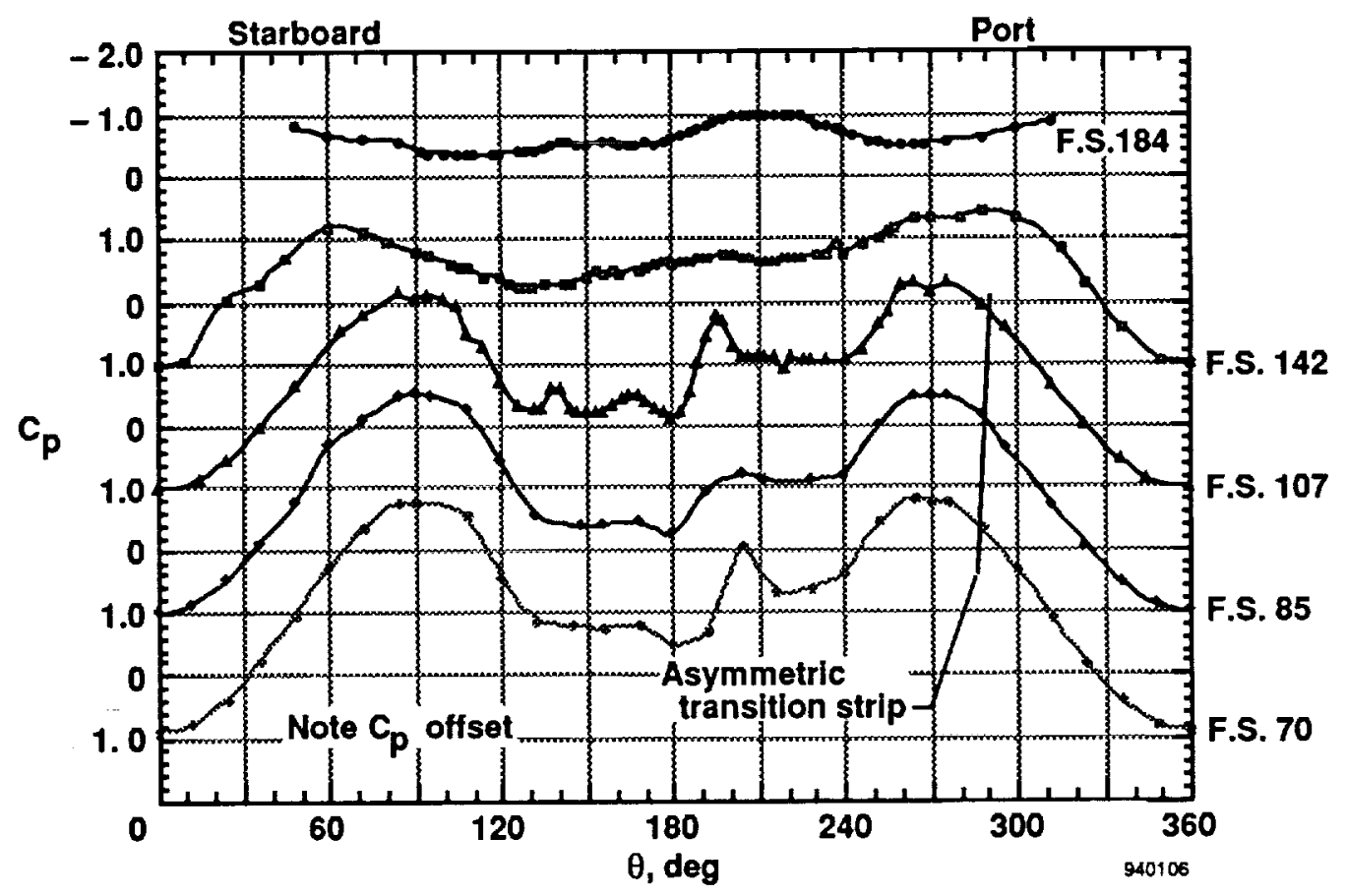

(b) Asymmetric transition strip; $\alpha=69.5^{\circ}, \beta=-0.7^{\circ}$.

Figure 8. Effect of asymmetric transition strips on F-18 HARV forebody pressure distributions. 


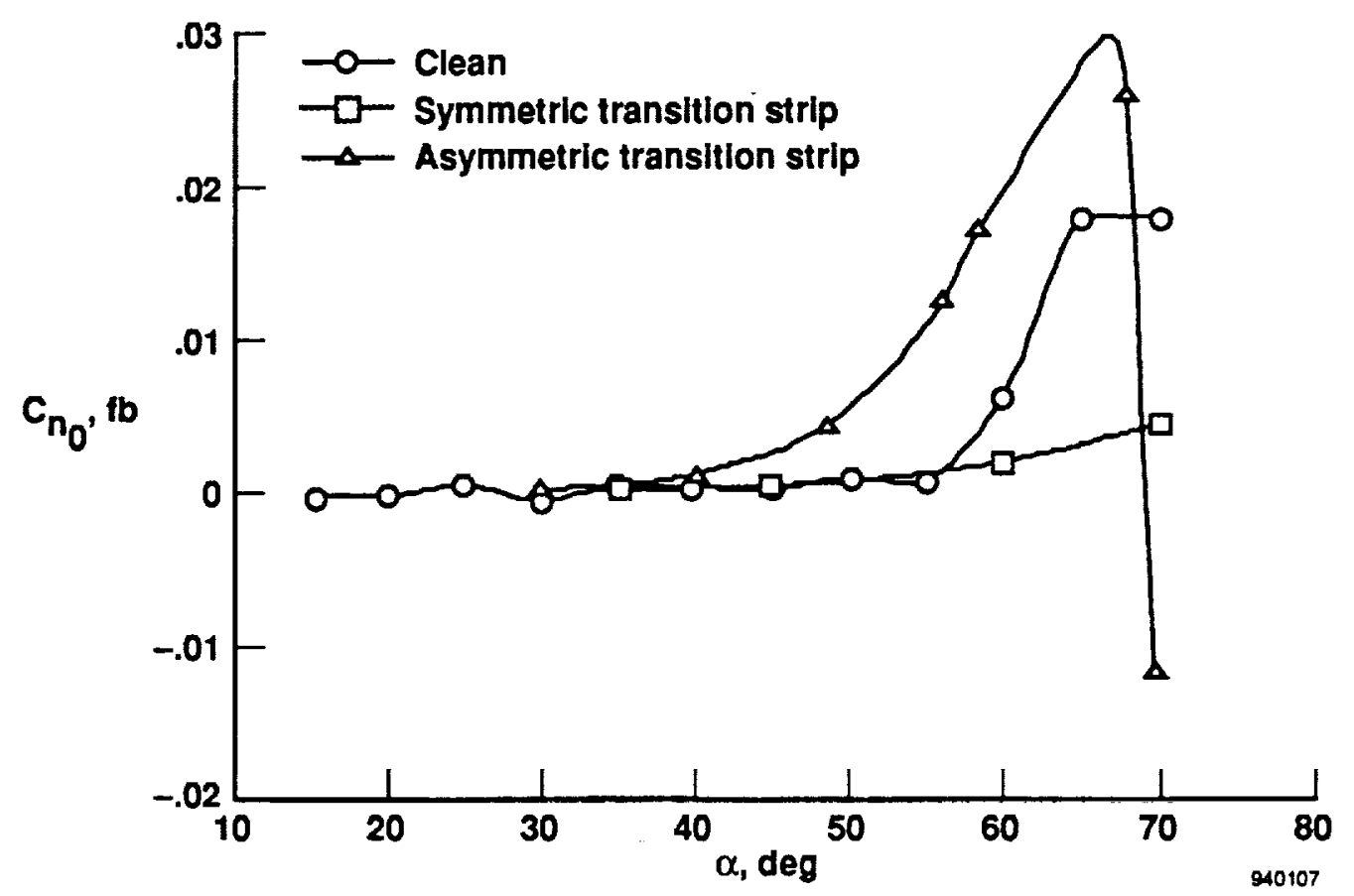

Figure 9. Effect of transition strips on F-18 HARV forebody yawing moment.

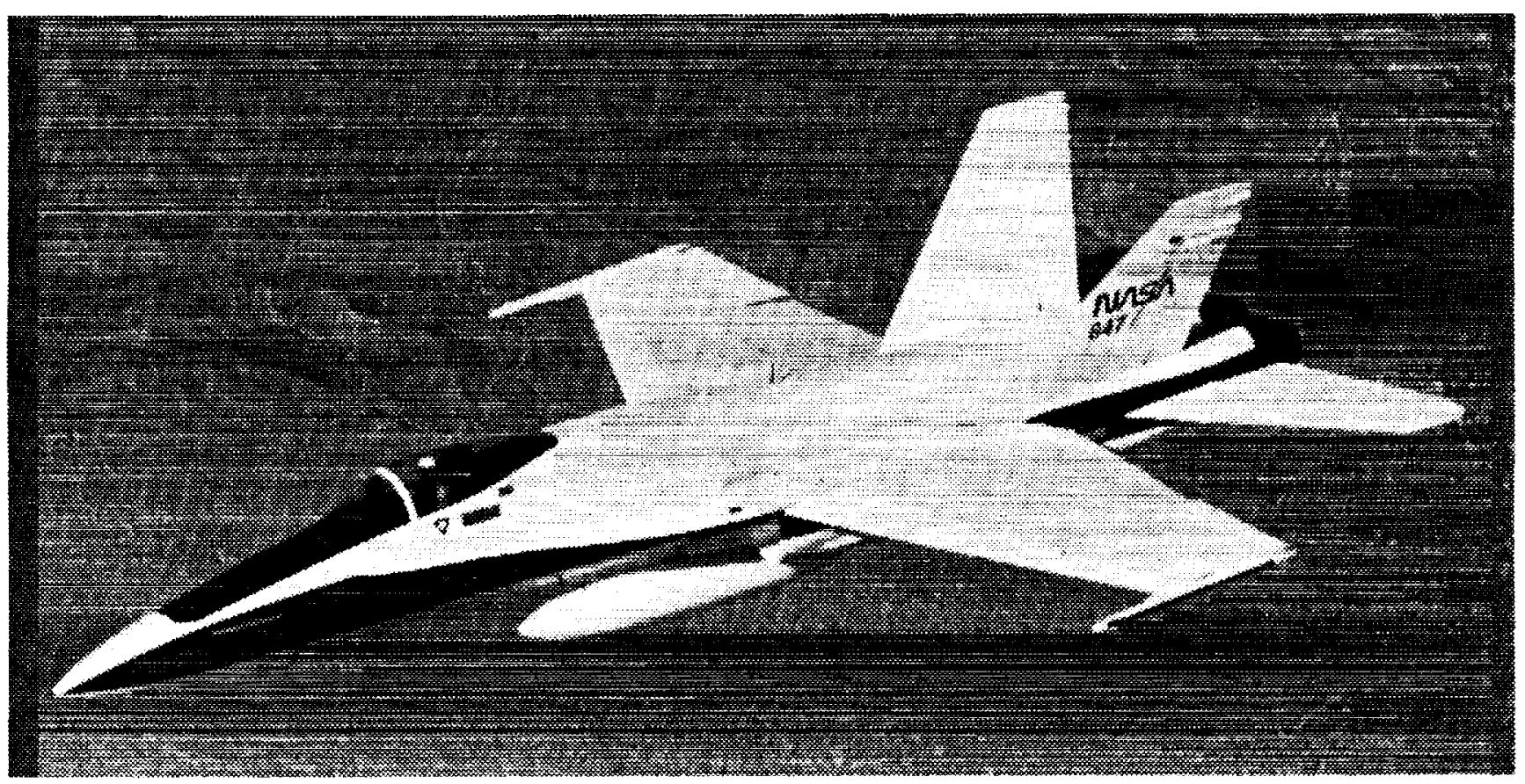

EC94-42478-20

Figure 10. F/A-18 aircraft (centerline store not installed for flights reported here). 


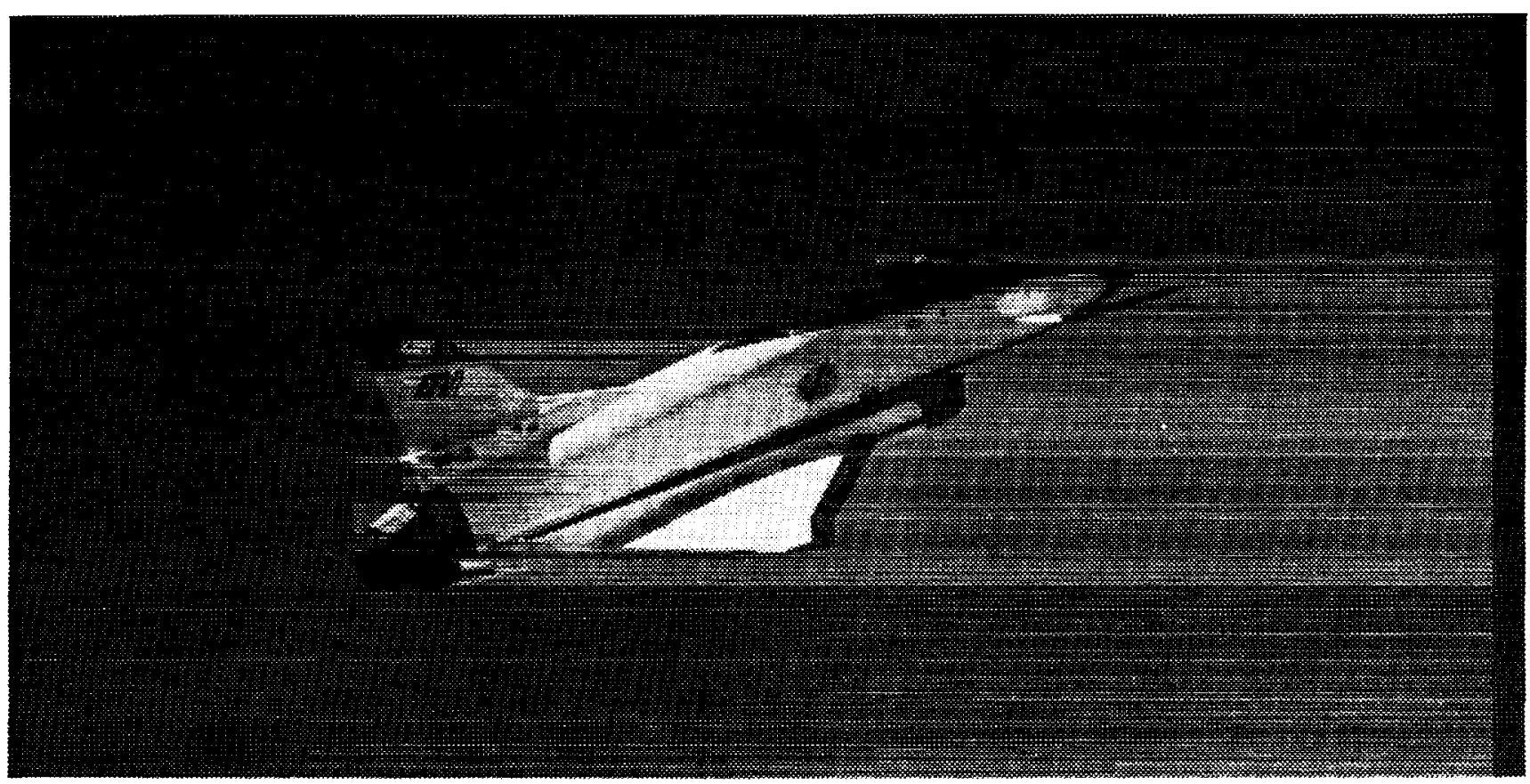

EC93-41063-10

Figure 11. X-31 aircraft in flight.

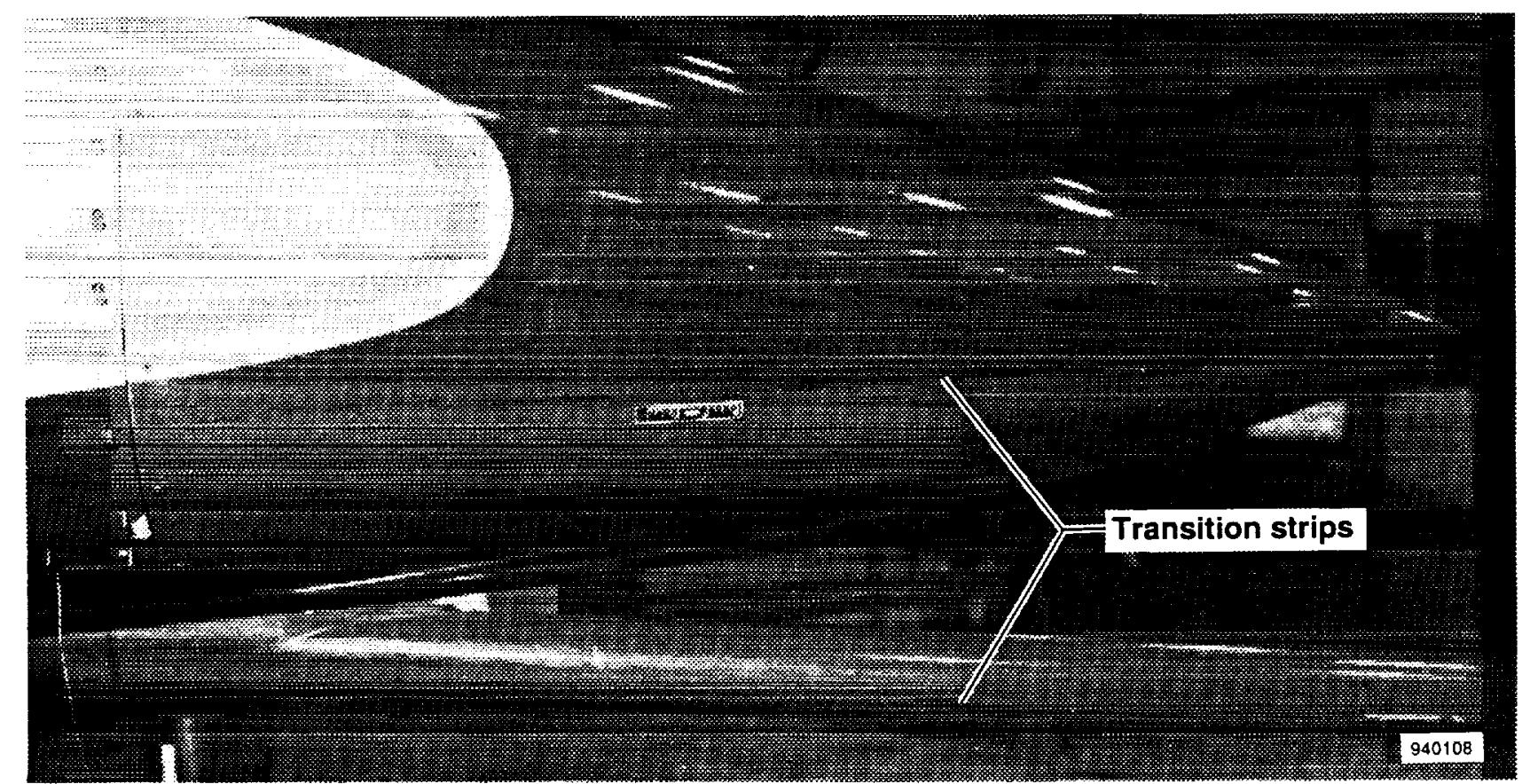

Figure 12. Boundary layer transition strips on X-31 forebody and noseboom. 


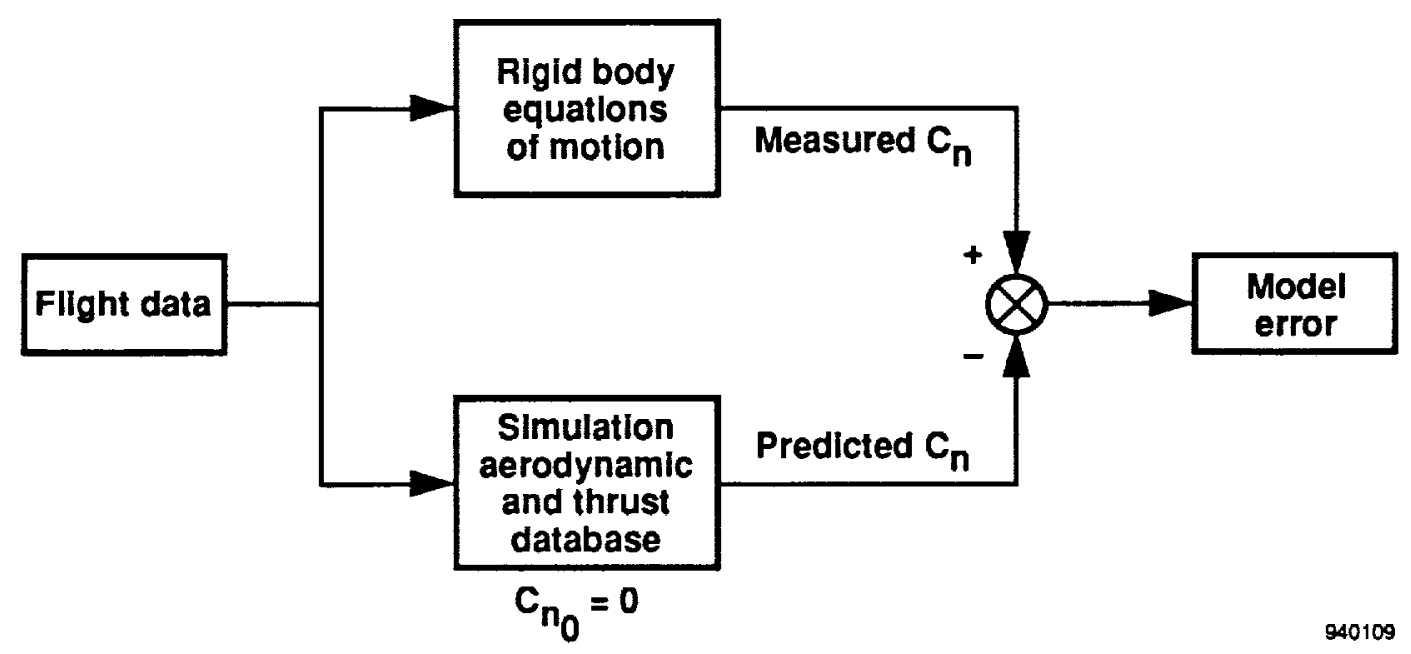

Figure 13. Asymmetry calculation model.

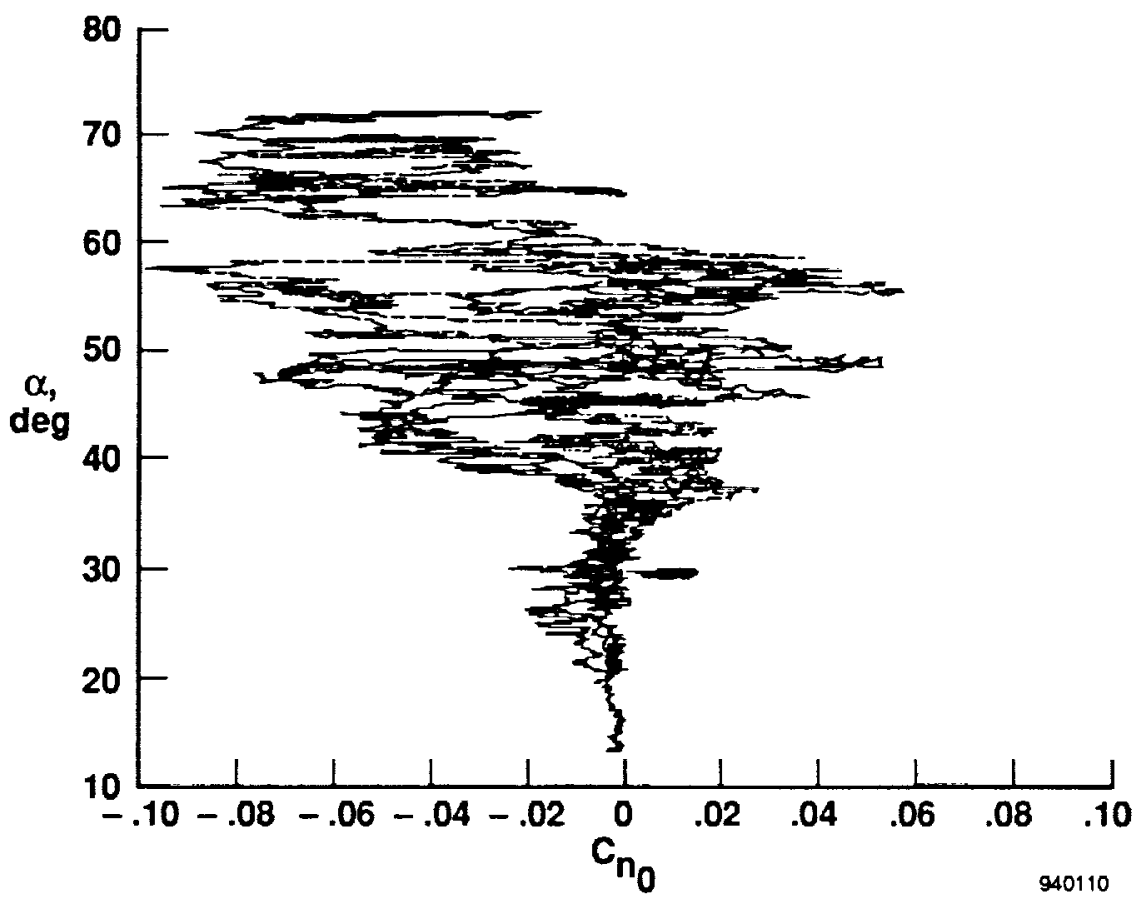

(a) Clean configuration.

Figure 14. X-31 ship-2 asymmetry characteristics. 


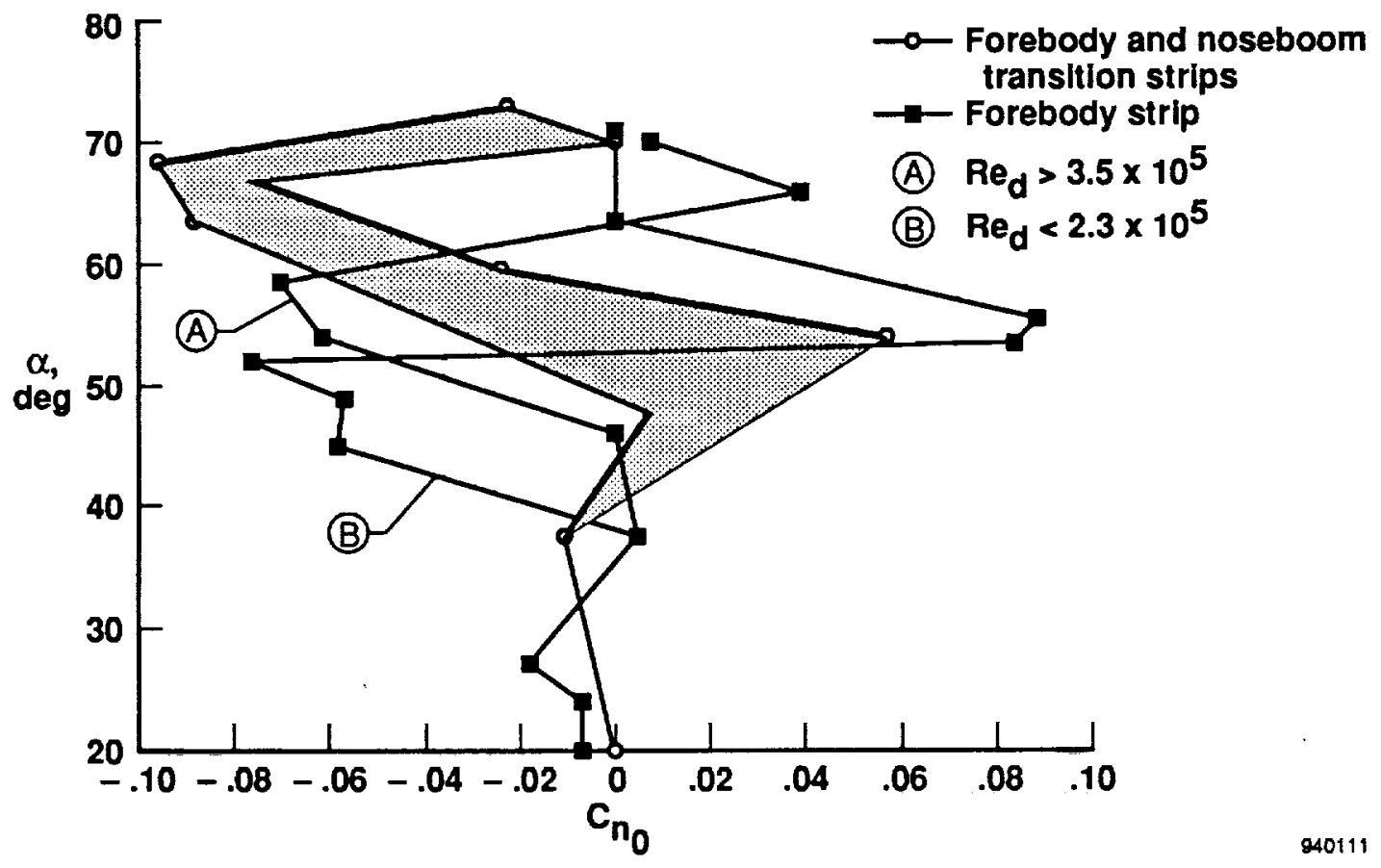

(b) With symmetric transition strips.

Figure 14. Concluded.

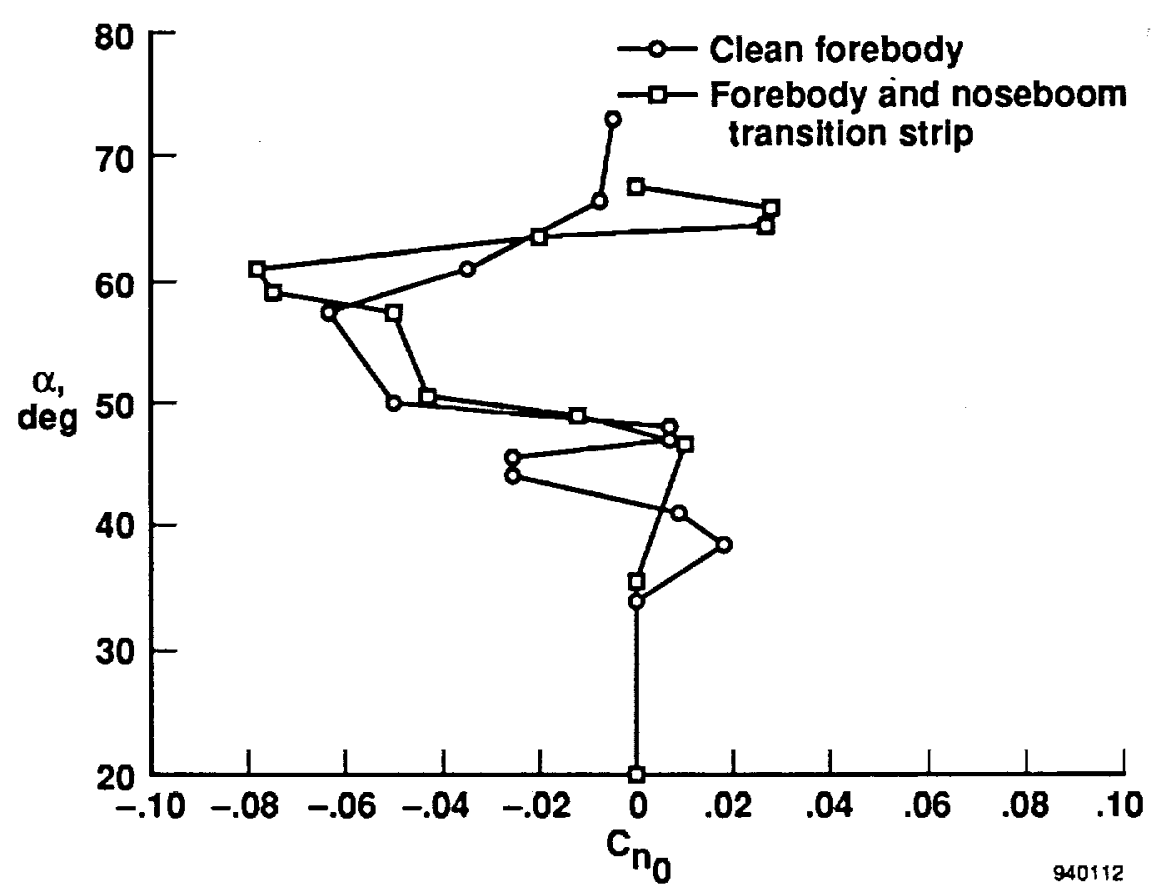

Figure 15. X-31 ship-1 asymmetry characteristics with and without transition strips. 


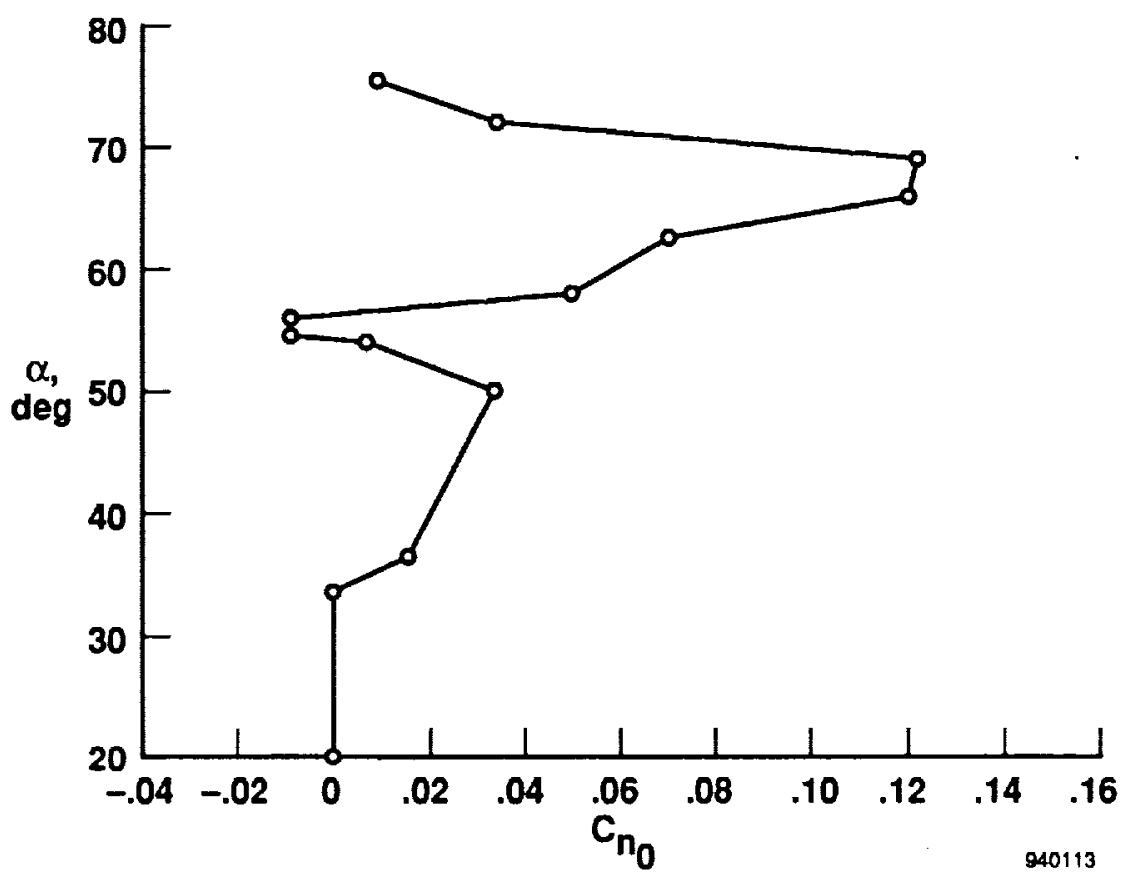

Figure 16. X-31 ship-2 yawing moment asymmetry from flight 73 departure.

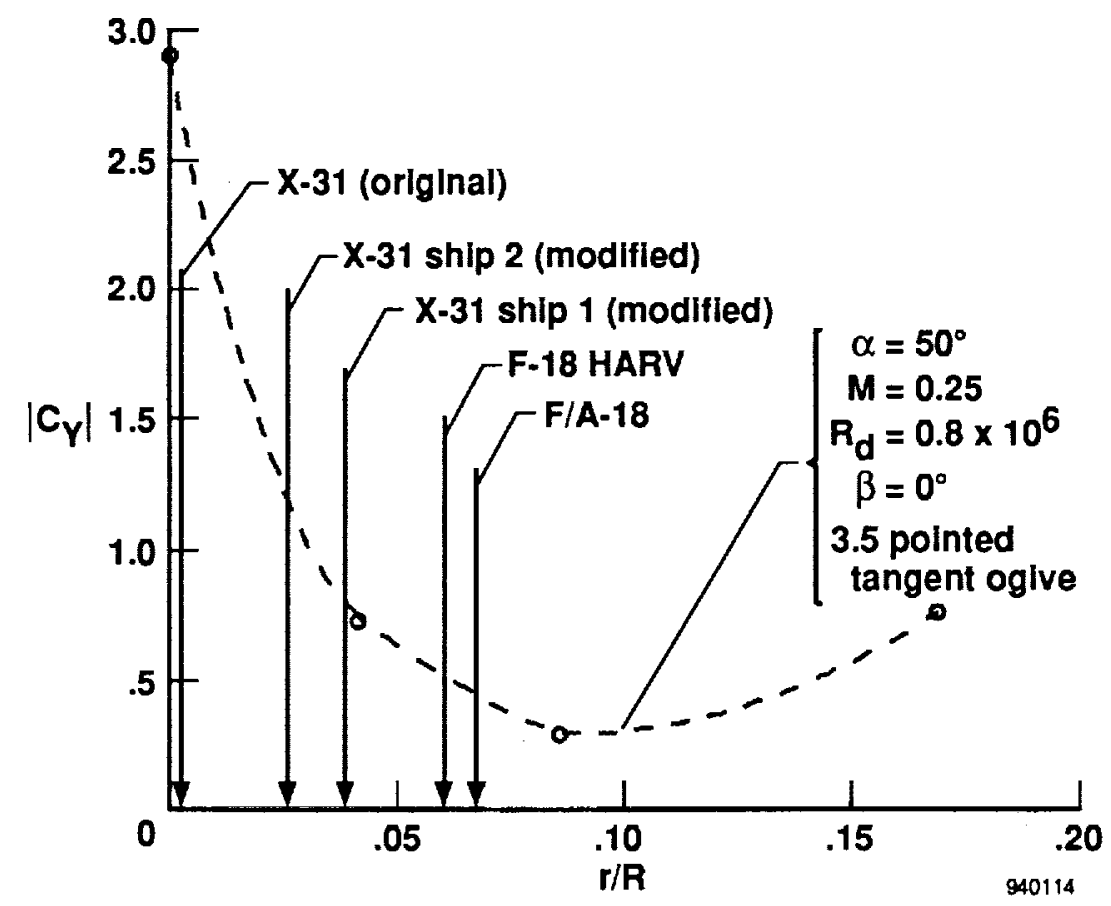

Figure 17. Effect of nose bluntness on side force (modified from fig. 71 in ref. 14). 


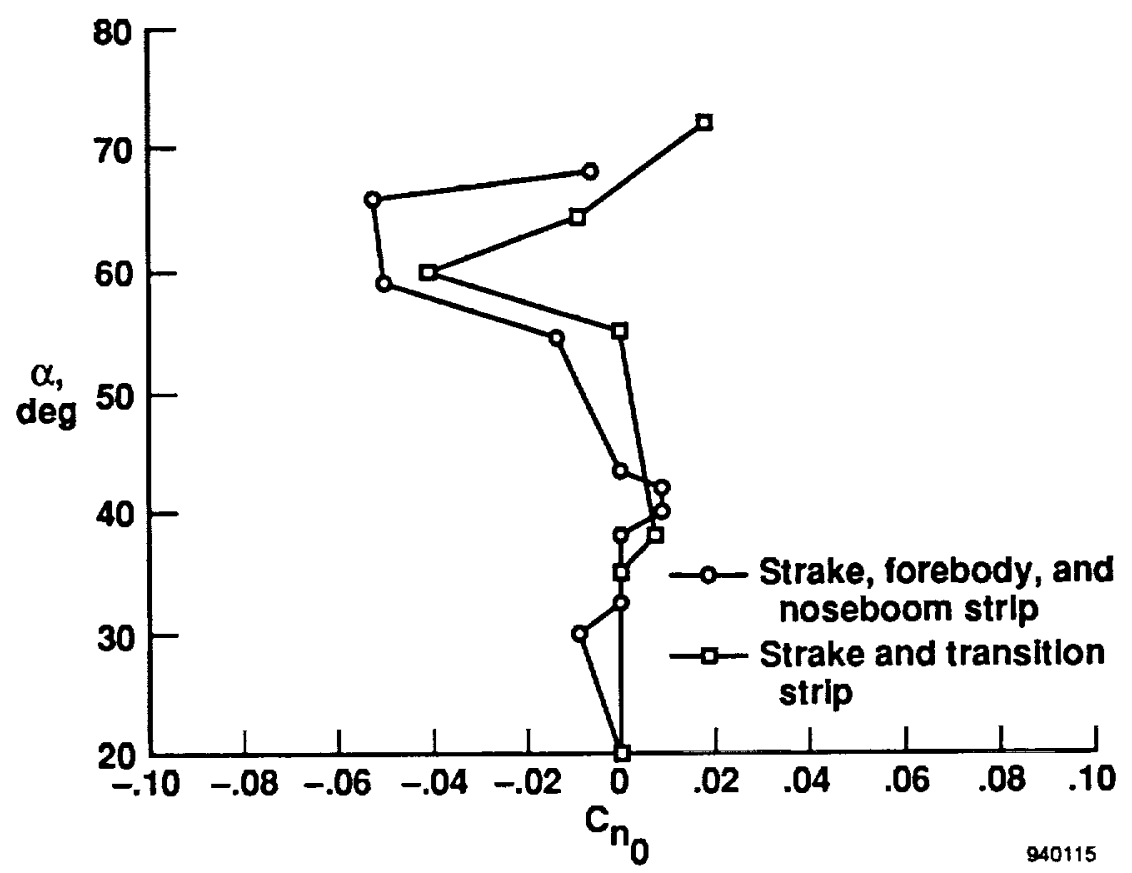

Figure 18. X-31 ship-1 forebody asymmetry characteristics with forebody strakes.

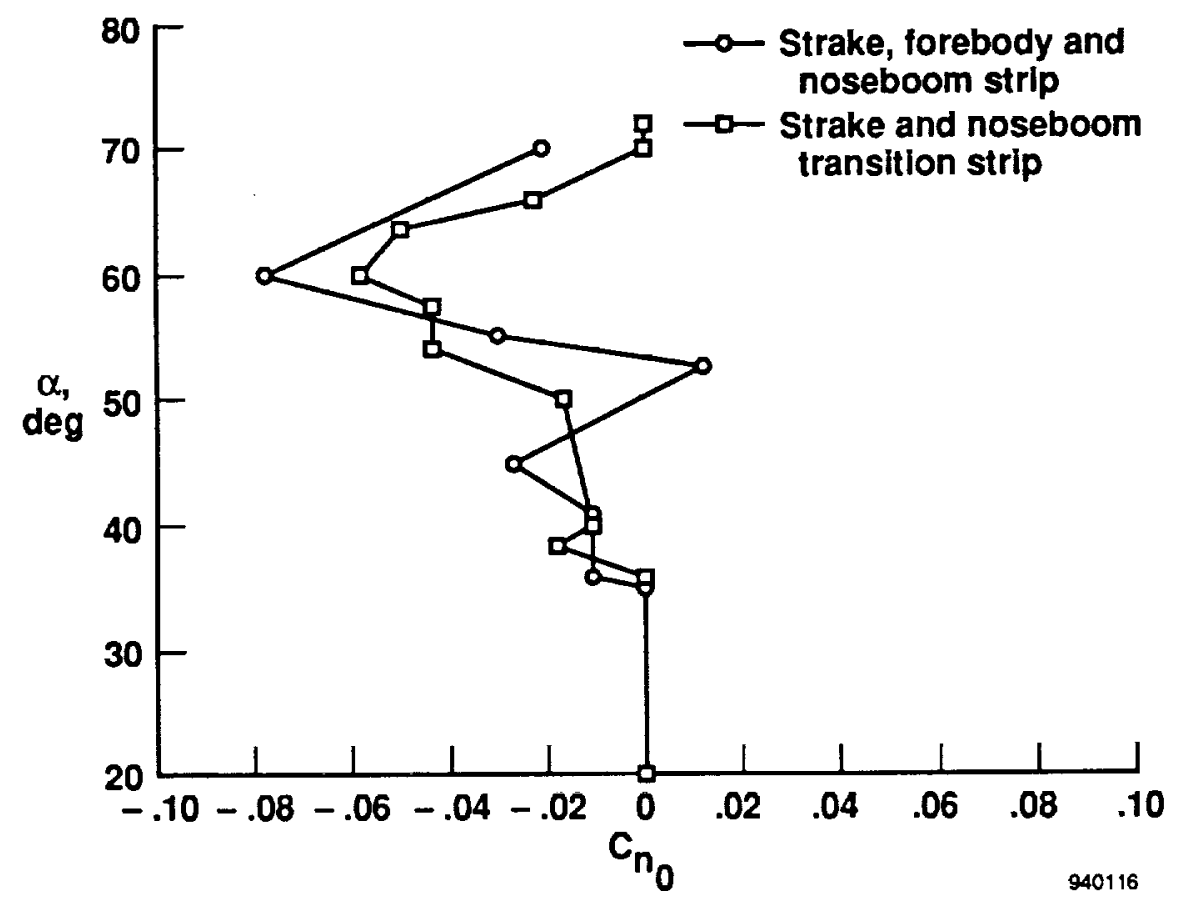

Figure $19 . \mathrm{X}-31$ ship- 2 forebody asymmetry characteristics with forebody strakes. 
Public reporting burden for this collection of intormation is estimated to average 1 hour per responte, including the time lor reviewing Instructions, tearching existing data sources, gathering and maintaining the data needed, and completing and revlewing the collection of information. Send comments regarding this burden estimate or any other aspect of this collection of information, including suggestions for reducing this burden, to Washington Headquarters Services, Directorate lor Information Operations and Reports, 1215 Jellerson Davis Hlghway, Sutte 1204. Arlington, VA 22202-4302, and to the Ollice of Management and Budget, Papenwork Feduction Project (0704-0189). Washington, DC 20503.

\begin{tabular}{|l|l|l|}
\hline 1. AGENCY USE ONLY (Leave blank) & $\begin{array}{c}\text { 2. REPOAT DATE } \\
\text { July } 1994\end{array}$ & $\begin{array}{l}\text { 3. REPORT TYPE AND DATES COVERED } \\
\text { Technical Memorandum }\end{array}$ \\
\hline
\end{tabular}

\section{TITLE AND SUBTITLE \\ Controlling Forebody Asymmetries in Flight-Experience With Boundary} Layer Transition Strips

6. AUTHOR(S)

David F. Fisher (NASA Dryden Flight Research Center, Edwards, Califomia) and Brent R. Cobleigh (PRC Inc., Edwards, Califormia)

7. PERFORMING ORGANIZATION NAME(S) AND ADDRESS(ES)

NASA Dryden Flight Research Center

P.O. Box 273

Edwards, California 93523-0273

9. SPONSOAING/MONOTORING AGENCY NAME(S) AND ADDRESS(ES)

National Aeronautics and Space Administration

Washington, DC 20546-0001
5. FUNDING NUMBERS

WU 505-68-71

8. PERFORMING ORGANIZATION REPORT NUMBER

H-1992

10. SPONSORINGMONITORING AGENCY REPORT NUMBER

NASA TM-4595

\section{SUPPLEMENTARY NOTES}

This was originally prepared as AIAA-94-1826 for the 6th Biennial Flight Test Conference, Colorado Springs, CO, June 20-23, 1994.

Unclassified-Unlimited

Subject Category 02

\section{ABSTRACT (Maximum 200 words)}

The NASA Dryden Flight Research Center has an ongoing program to investigate aircraft flight characteristics at high angles of attack. As part of this investigation, longitudinal boundary layer transition strips were installed on the F-18 HARV forebody, a preproduction F/A-18 radome with a nose-slice tendency, and the X-31 aircraft forebody and noseboom to reduce asymmetric yawing moments at high angles of attack. The transition strips were effective on the F-18 HARV at angles of attack above $60^{\circ}$. On the preproduction F/A-18 radome at an angle of attack near $50^{\circ}$ the strips were not effective. When the transition strips were installed on the X-31 noseboom, a favorable effect was observed on the yawing moment dynamics but the magnitude of the yawing moments was not decreased.

\section{SUBJECT TERMS}

Boundary layer separation; Boundary layer transition; F-18 aircraft; Flight tests; Forebodies; Pressure distribution; Vortices; X-31 aircraft; Yawing moments

\begin{tabular}{|c|c|c|}
\hline $\begin{array}{l}\text { 17. SECURITY CLASSIFICATION } \\
\text { OF REPORT }\end{array}$ & $\begin{array}{l}\text { 18. SECURITY CLASSIFICATION } \\
\text { OF THIS PAGE }\end{array}$ & $\begin{array}{l}\text { 19. SECURITY CLASSIFICATION } \\
\text { OF ABSTRACT }\end{array}$ \\
\hline Unclassified & Unclassified & Unclassified \\
\hline
\end{tabular}
$\mathrm{AO} 3$

20. LIMITATION OF ABSTRACT

\section{Unlimited}

